\title{
Utilizing Laser-Activation of Photothermal Plasmonic Nanoparticles to Induce On-Demand Drug Amorphization Inside a Tablet
}

Nele-Johanna Hempel, ${ }^{[a]}$ Padryk Merkl, ${ }^{[b]}$ Shno Asad, ,c] Matthias Manne Knopp, ${ }^{[\mathrm{d}]}$ Ragna Berthelsen, ${ }^{[a]}$

Christel A.S. Bergström, ${ }^{[e]}$ Alexandra Teleki, ${ }^{[c]}$ Georgios A. Sotiriou, ${ }^{[b]}$ Korbinian Löbmann ${ }^{*[a]}$ 


\section{Experimental Procedures}

\section{On-demand amorphization:}

Table S1: Overview of the parameters chosen for the on-demand drug amorphization, namely laser intensity [W $\left.\mathrm{cm}^{-2}\right]$ and exposure time [sec] for each tablet. Celecoxib (CCX); Plasmonic nanoparticles (PN)

\begin{tabular}{|c|c|c|c|c|c|}
\hline \multirow[b]{3}{*}{$\begin{array}{l}\text { Laser } \\
\text { intensity } \\
{\left[\mathrm{W} \mathrm{cm}{ }^{2}\right]}\end{array}$} & \multicolumn{5}{|c|}{ Exposure time [sec] } \\
\hline & \multicolumn{5}{|l|}{ Tablet composition } \\
\hline & $\begin{array}{l}30 \text { wt } \% \text { CCX, } \\
0.25 \text { wt } \% \text { PN }\end{array}$ & $\begin{array}{l}30 \mathrm{wt} \% \mathrm{CCX} \\
0.1 \mathrm{wt} \% \mathrm{PN}\end{array}$ & $\begin{array}{l}50 \text { wt } \% \text { CCX, } \\
0.25 \text { wt } \% \text { PN }\end{array}$ & $\begin{array}{l}50 \text { wt } \% \text { CCX, } \\
0.1 \text { wt } \% \text { PN }\end{array}$ & $\begin{array}{l}30 \text { wt } \% \text { CCX, } \\
0 \text { wt } \% \text { PN }\end{array}$ \\
\hline 0.55 & 180,720 & 180,720 & 180,720 & 180,720 & - \\
\hline 0.74 & 180,720 & 180,720 & 180,720 & 180,720 & - \\
\hline 0.93 & $180,360,540,720$ & 180,720 & $180,360,540,720$ & 180,720 & - \\
\hline 1.12 & $\begin{array}{l}60,90,120,150 \\
180,210\end{array}$ & $\begin{array}{l}180,360,540,720 \\
900\end{array}$ & $\begin{array}{l}60,90,120,150 \\
180\end{array}$ & $\begin{array}{l}180,360,540 \\
720,900\end{array}$ & 900 \\
\hline 1.31 & $\begin{array}{l}60,90,120,150 \\
180\end{array}$ & $\begin{array}{l}60,120,180,240 \\
360,480\end{array}$ & $\begin{array}{l}60,90,120,150 \\
180\end{array}$ & $\begin{array}{l}60,120,180,240 \\
360,480\end{array}$ & 480 \\
\hline
\end{tabular}

\section{Matlab script:}

The following Matlab script was used to extract the temperature measurements of the surface of the tablet from the thermal IR camera. The thermal IR camera takes pictures during the measurement, whereas the maximum temperature of each picture is taken.

inputdir ='filepath'

$\mathrm{S}=\operatorname{dir}\left(\right.$ fullfile(inputdir, $\left.\left.{ }^{* *} . x I s x^{\prime}\right)\right)$;

Sa=dir(fullfile(inputdir,'*.bmt'));

TAm=[];

times=[];

for $\mathrm{k}=1$ :numel(S)

fnm = fullfile(inputdir, $S(k) \cdot$ name);

AT $=$ xlsread $(f n m)$;

TAm=horzcat $(\mathrm{TAm}, \max (\max (\mathrm{AT})))$;

times=[times,gettime(Sa(k).date)];

end

times=times-times $(1)$;

plot(times, TAm)

data=vertcat(times, TAm);

writecsv(transpose(data),[inputdir 'loriginplot.csv']);

function time=gettime(test)

test=test(13:end);

$\mathrm{h}=$ str2num(test $(1: 2))^{\star} 3600$;

$\mathrm{m}=\operatorname{str} 2$ num $(\operatorname{test}(4: 5))^{*} 60$;

$s=$ str2num(test $(7: 8)$ );

time $=\mathrm{h}+\mathrm{m}+\mathrm{s}$;

end

\section{Thermal analysis and quantification:}

3.1 Calibration and fitting of the fusion enthalpy: 
Quantification of residual crystallinity was enabled by calibrating the fusion enthalpy of CCX in PVP, as the fusion is linearly correlated to the crystallinity of CCX.[1] Therefore, a calibration curve was established using $100 \mathrm{mg}$ mixtures containing $10-50$ wt $\%$ CCX in PVP in 10 wt\% steps. The mixtures were prepared by mortar and pestle. 2-4 mg of each mixture was weighed into a Tzero aluminum pan with a perforated hermetically sealing lid. The fusion enthalpy was determined in the total heat flow using a modulated DSC (mDSC) with a heating rate of $3^{\circ} \mathrm{C} \mathrm{min}-1$ from $20^{\circ} \mathrm{C}$ to $190{ }^{\circ} \mathrm{C}$ with an amplitude of $1{ }^{\circ} \mathrm{C}$ minand over a period of $50 \mathrm{sec}$ after equilibrating at $20^{\circ} \mathrm{C}$ for $2 \mathrm{~min}$. Due to the perforation of the lid, the water evaporated during the heating, hence, it did not disturb the signal. The fusion enthalpy was determined using the TA Instruments TRIOS software (version 4.1.1). Each calibration point was determined as a duplicate $(n=2)$. The sample mass was corrected by the actual water content of each mixture. Due to the hygroscopicity of PVP in the mixtures and its different amounts, the water content of each mixture was determined separately (Table S2). The calibration curve was plotted and fitted with a polynomial function of second degree, with an intercept of 0, using OriginPro 2017 (Academia) version 9.4 from OriginLab Corporation (Northampton, MA, USA) (Figure S1, Table S3).

Table S2: Water content of the mixtures used for the DSC calibration $(n=3)$.

\begin{tabular}{|l|l|}
\hline CCX [wt\%] in PVP & Water content (Mean \pm SD, $\boldsymbol{n}=3$ ) [wt\%] \\
\hline 11 & $7.75 \pm 0.67$ \\
\hline 20 & $6.81 \pm 0.60$ \\
\hline 31 & $5.66 \pm 0.21$ \\
\hline 42 & $5.22 \pm 0.19$ \\
\hline 51 & $4.50 \pm 0.28$ \\
\hline
\end{tabular}

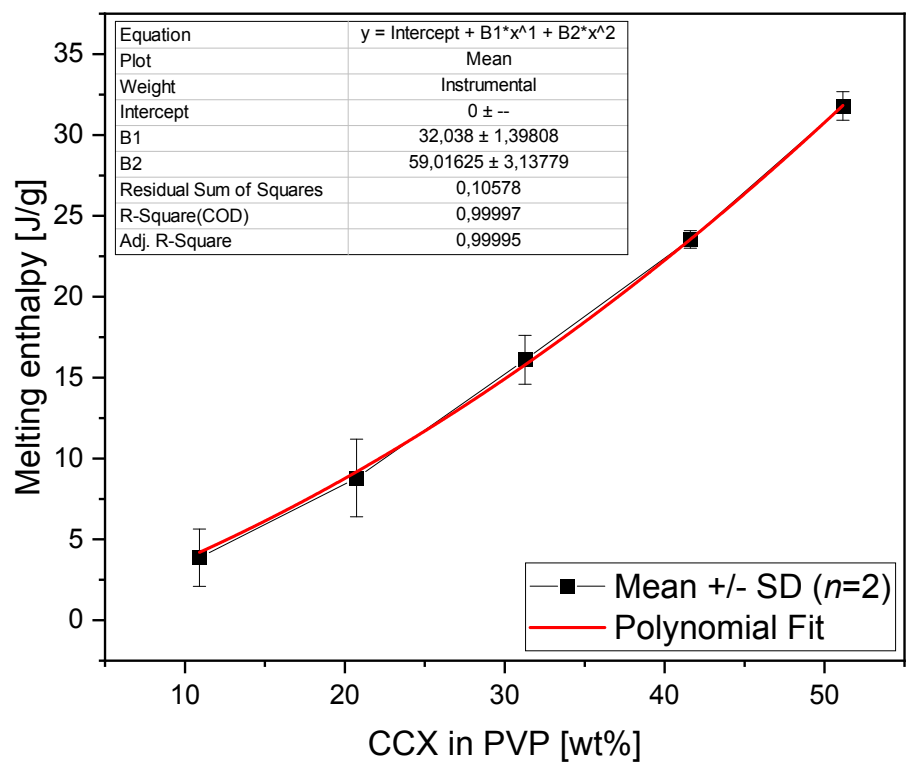

Figure S1: Calibration curve for the fusion enthalpy using the DSC

Table S3: Calibration data points $(n=2)$.

\begin{tabular}{|l|l|}
\hline CCX [wt\%] in PVP & $\begin{array}{l}\text { Melting enthalpy (Mean } \pm \text { SD } \\
(\boldsymbol{n}=\mathbf{2}))\left[\mathbf{J ~ g}^{\mathbf{1}}\right]\end{array}$ \\
\hline 11 & $3.86 \pm 1.77$ \\
\hline 20 & $8.80 \pm 2.40$ \\
\hline 31 & $16.10 \pm 1.51$ \\
\hline 42 & $23.54 \pm 0.54$ \\
\hline 51 & $31.80 \pm 0.88$ \\
\hline
\end{tabular}

\section{Solid-state characteristics:}




\subsection{XRPD using a variable temperature stage:}

To investigate the effect of the temperature on the solid state characteristics, variable temperature stage XRPD was conducted for the four mixtures with plasmonic nanoparticles (Table 1) as well as pure CCX. The diffractograms were recorded in reflection mode using a X'Pert Pro diffractometer from PANanalytical (Eindhoven, The Netherlands) with Cu Ka radiation $(\lambda=1.54187 \AA$ ). Diffractograms were recorded from $4-40.003^{\circ} 2 \theta$ at $45 \mathrm{kV}$ and $40 \mathrm{~mA}$ using a step size of $0.0131303^{\circ}$ and a scan speed of $0.164129^{\circ} \mathrm{s}^{-1}$. The temperature was controlled by placing the samples into an Anton Paar $\mathrm{CHC}$ Chamber equipped with an Anton Paar TCU 110 Temperature Control Unit from Anton Paar Nordic AB (Ballerup, Danmark). Approximately 10-15 mg of mixture was placed on a PT 100 sample holder. The diffractograms were recorded at the temperatures 40, 60, 80, 100, 120, 140,160 and $180^{\circ} \mathrm{C}$. Between each measurement the temperature was raised with a rate of $5^{\circ} \mathrm{C} \mathrm{min}{ }^{-1}$. Before and after the measurement at 40,60 and $80^{\circ} \mathrm{C}$ was an isothermal period of $1 \mathrm{~min}$ and at $100,120,140,160$ and $180^{\circ} \mathrm{C}$ an isothermal period of $2 \mathrm{~min}$. The obtained diffractograms were analyzed using the X'Pert Data Viewer software (version 1.2).

\section{Quantification of CCX and qualification of degradation using liquid chromatography:}

\subsection{Linearity to quantify CCX in solution:}

Six solutions containing CCX in concentrations 2-12 $\mu \mathrm{g} \mathrm{mL}^{-1}$ were analyzed. The area under the curve for the CCX peak proved to be linear to its concentration in this range. The regression line equation was found to be: $y=55927 x+4.5432 ; R^{2}$ $=0.9997$ (Equation 1).

\subsection{Solutions of tablets, mixtures and tablets exposed to laser radiation:}

Tablets exposed to laser radiation were tested for degradation. Therefore, the tablets were mortared and partly weighed into $100.0 \mathrm{~mL}$ volumetric flasks. Subsequently, the obtained solutions were diluted in accordance with the concentration range described in 5.1. Furthermore, the dilutions were prepared for injection as described in the main manuscript. The tablets chosen correspond to tablets that became completely amorphous. Additionally, the mixtures (data not shown) as well as tablets not exposed to laser radiation of each composition were tested for quantification of the CCX amount.

\section{Degradation analysis by mass spectroscopy:}

Mass spectroscopy analysis for degradation was conducted on a Finnigan TSQ Quantum Ultra AM from Thermo Scientific TM (Waltham, MA, USA). Celecoxib and a mixture of irradiated tablets were both tuned by the same method and were inserted directly into the MS without HPLC column upfront. The spray voltage was set to 5000 , the sheath gas pressure was at 10 and the ion sweep gas pressure at 0 . The aux gas pressure was set to 5 at a capillary temperature of $350 \mathrm{~K}$. The tube line offset was 120 with a skimmer offset of 0 . Celecoxib and the sample were both injected at a flow rate of $0.2 \mathrm{~mL} \mathrm{~min}^{-1}$ with a collision energy of 35 and Q2 CID gas of 1.5. The spectra is not shown, but can be obtained upon request. 


\section{Results and Discussion}

\section{Figure S2:}

Figure S2 shows a) a schematic of the manufacturing of the plasmonic nanoparticles (PN) with a dielectric spacer and $b$ ) their absorbance in the near-IR region as well as c) a TEM image of the obtained plasmonic nanoaggregates (size ca. $10 \mathrm{~nm}$ ).

a)

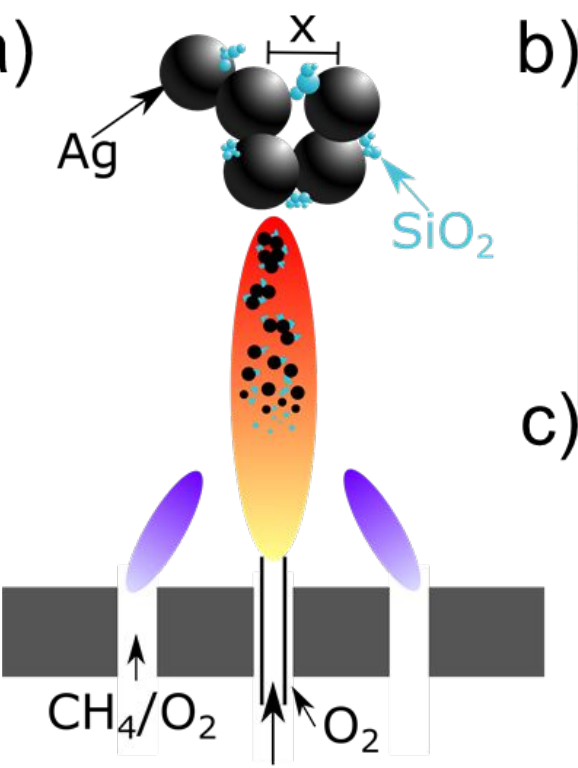

\section{Liquid precursor}

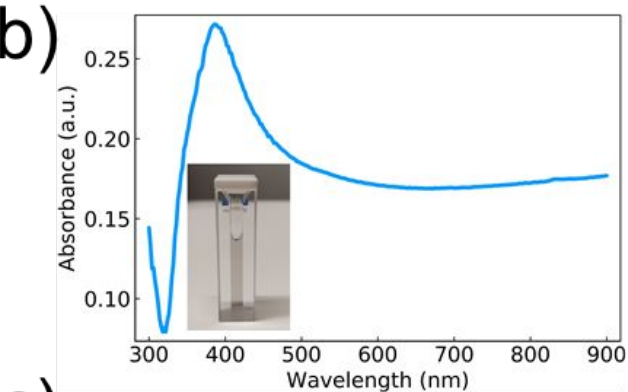

c)

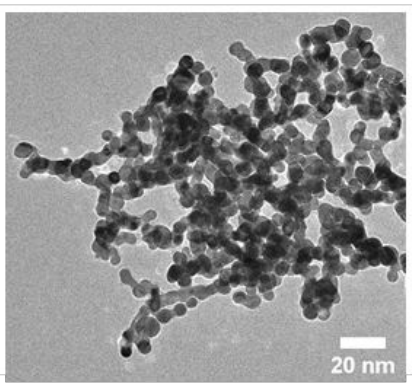

Figure S2: a) Dielectric spacer $\left(\mathrm{SiO}_{2}\right)$ between the plasmonic nanoparticles (PN), here Ag, to b) obtain absorption in the near-IR region; c) TEM Images of the produced nanoaggregates. 


\section{Figure S3:}

Figure S3 shows the definition of the critical temperature threshold (threshold) for on demand amorphization of CCX in PVP $\left(80^{\circ} \mathrm{C}-85^{\circ} \mathrm{C}\right)$. In all cases little (undetected) or no amorphization occurred below $80^{\circ} \mathrm{C}$ (dashed grey line). The threshold is above the $T_{\mathrm{g}}$ of the pure polymer $\left(T_{\mathrm{g}}=65.6 \pm 4.0^{\circ} \mathrm{C}\right.$ (with water of the bulk polymer)). The water content of the bulk polymer PVP is $6.24 \pm 1.67 \mathrm{wt} \%$ (Mean $\pm \mathrm{SD}, n=3$ ). The water content inside the tablets before exposure to laser radiation is reported in Table S8 (between 3.30-4.95 wt\%), which is in line with the reported water content of the polymer as the other tablet components are water-free. That the threshold is above the $T_{\mathrm{g}}$ of the polymer can be explained by two possible reasons: (i) The $T_{\mathrm{g}}$ is a kinetic process, hence with higher heating rates, as recorded in the experiment (approx. $60{ }^{\circ} \mathrm{C} / \mathrm{min}$ ) (Figure S3 and Figure 2), the $T_{\mathrm{g}}$ will be higher than measured by DSC ${ }^{[2]}$ and (ii) the viscosity decrease above the $T_{\mathrm{g}}$ of the polymer does not match the predictions of the Stoke-Einstein Equation. The Stoke-Einstein Equation describes the correlation between viscosity and diffusion coefficient (part of the Noyes-Whitney Equation), however the diffusion is neither viscosity controlled nor does the viscosity decrease remarkably until $\left[T_{\mathrm{g}}+(15-25){ }^{\circ} \mathrm{C}\right]=T_{\mathrm{c}}$ (critical $\left.T_{\mathrm{g}}\right) \cdot{ }^{[3]} T_{\mathrm{c}}$ (calculated: $(80.6-90.6) \pm 4.0^{\circ} \mathrm{C}$ ) matches the experimentally observed threshold. Similar observations have been described for hot-melt extrusion, where the fusion of the drug into the mobile polymer occurs at temperatures above the $T_{\mathrm{g}} \cdot{ }^{[4]}$
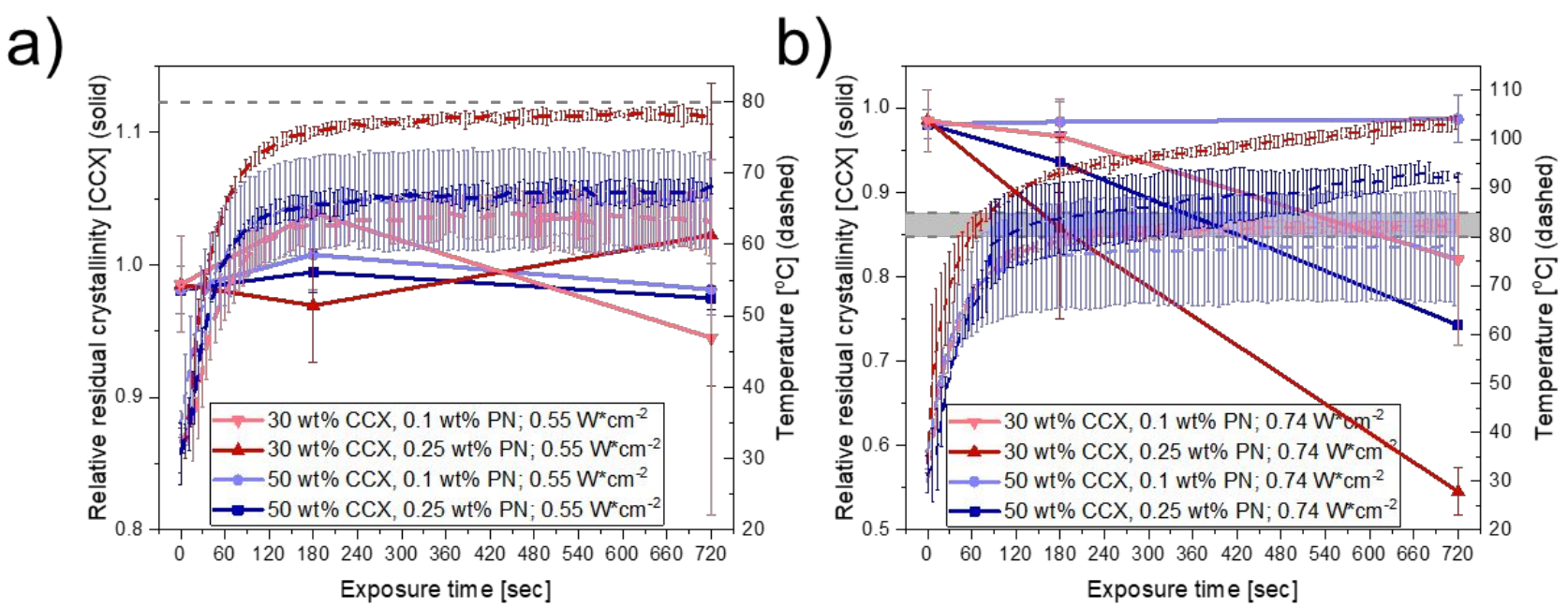

Figure S3: Definition of the critical temperature threshold (experimentally); a) relative residual crystallinity of celecoxib (CCX) plotted (solid lines) and the temperature (dashed lines) against the exposure time for the laser intensity $0.55 \mathrm{~W} \mathrm{~cm}^{-2}$. b) relative residual crystallinity of CCX (solid lines) and the temperature (dashed lines) plotted against the exposure time for the laser intensity $0.74 \mathrm{~W} \mathrm{~cm}^{-2}$. The grey area, i.e. the critical temperature threshold, starts at $80^{\circ} \mathrm{C}$ and ends at $85^{\circ} \mathrm{C}$ and marks the temperature range in which the onset of amorphization occurs. Lines were drawn to guide the eye. Mean $\pm \mathrm{SD}$ $(n=2)$ for left $y$-axis; Mean $\pm \mathrm{SD}(n=3)$ for right y-axis. PN: Plasmonic nanoparticle(s). 


\section{Table S4:}

Table S4: Exposure times [sec] needed to obtain complete amorphization for each tablet composition at different laser intensities [W $\mathrm{cm}^{-2}$ ]. The degree of amorphization was measured by DSC (1, quantitatively) and XRPD (2, qualitatively). a) No data points between (1) and (2). "-"No full amorphization was reached after the max. exposure time. The DSC data was used for Figure 2 and 3 in the main part of this manuscript.

\begin{tabular}{|c|c|c|c|c|}
\hline \multirow[b]{3}{*}{$\begin{array}{l}\text { Laser intensity } \\
{\left[\mathrm{W} \mathrm{cm}^{2}\right]}\end{array}$} & \multicolumn{4}{|c|}{ Exposure time to complete amorphization [sec] } \\
\hline & \multicolumn{4}{|c|}{ Tablet composition } \\
\hline & $\begin{array}{l}50 \text { wt } \% \text { CCX, } \\
0.1 \text { wt } \% \text { PN }\end{array}$ & $\begin{array}{l}50 \text { wt } \% \text { CCX, } \\
0.25 \text { wt } \% \text { PN }\end{array}$ & $\begin{array}{l}30 \text { wt } \% \text { CCX, } \\
0.1 \text { wt } \% \text { PN }\end{array}$ & $\begin{array}{l}30 \text { wt } \% \text { CCX, } \\
0.25 \text { wt } \% \text { PN }\end{array}$ \\
\hline 0.55 & - & - & - & - \\
\hline 0.74 & - & - & - & - \\
\hline 0.93 & - & (1) $720 ;(2) 720$ & - & (1) $720 ;(2) 720$ \\
\hline 1.12 & (1) $720 ;(2) 900_{a}$ & (1) $180 ;(2) 180$ & (1) $900 ;(2) 900$ & (1) $180 ;(2) 210_{a}$ \\
\hline 1.31 & (1) 480; (2) 480 & (1) $180 ;(2) 180$ & (1) $360 ;(2) 480_{a}$ & (1) $150 ;(2) 150$ \\
\hline
\end{tabular}

\section{Figure S4:}

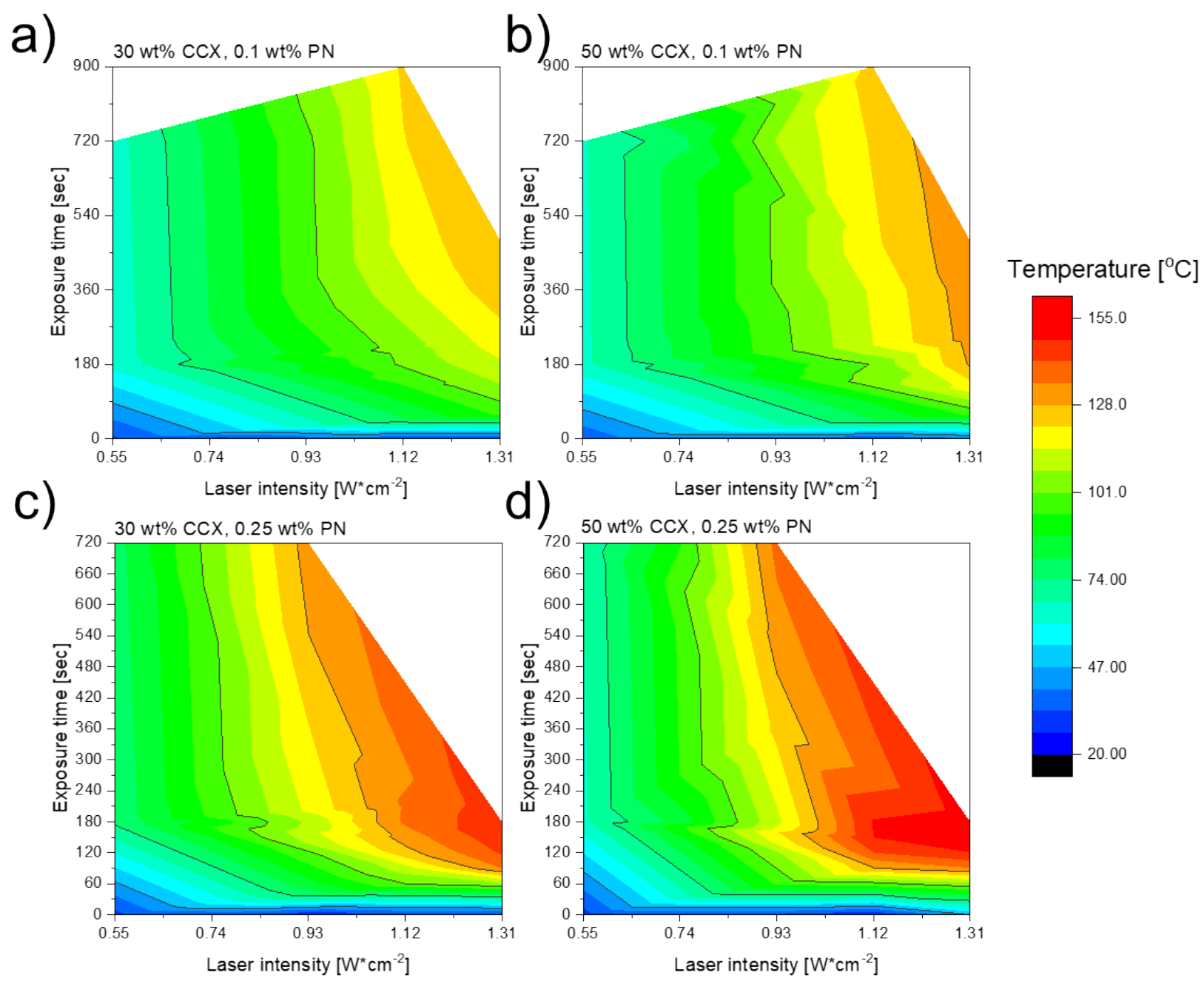

Figure S4: a-d) Exposure time [sec] plotted against the laser intensity [ $\mathrm{W} \mathrm{cm}^{-2}$ ] as a function of temperature [ $\left.{ }^{\circ} \mathrm{C}\right]$ for the tablets with a) $30 \mathrm{wt} \%$ celecoxib (CCX), 0.1 wt\% plasmonic nanoparticles (PN); b) 50 wt\% CCX, 0.1 wt \% PN; c) 30 wt \% CCX, 0.25 wt \% PN; d) 50 wt \% CCX, 0.25 wt $\%$ PN. 


\section{Figure S5:}

Figure S5 shows the onset of fusion for $30 \mathrm{wt} \%$ and $50 \mathrm{wt} \%$ celecoxib (CCX) in the presence of the polymer PVP. It can be seen that the onset of fusion is depressed compared to the pure compound $\left(163^{\circ} \mathrm{C}\right.$ ) (see also Figure $\mathrm{S} 5 \mathrm{~b}$ ) ${ }^{[5]}$ and that the onset of fusion is higher for mixtures containing $50 \mathrm{wt} \% \mathrm{CCX}$ compared to $30 \mathrm{wt} \% \mathrm{CCX}$, as less impurity is present in form of the polymer PVP. This data is supported by the XRPD variable temperature stage results shown in Figure S6.
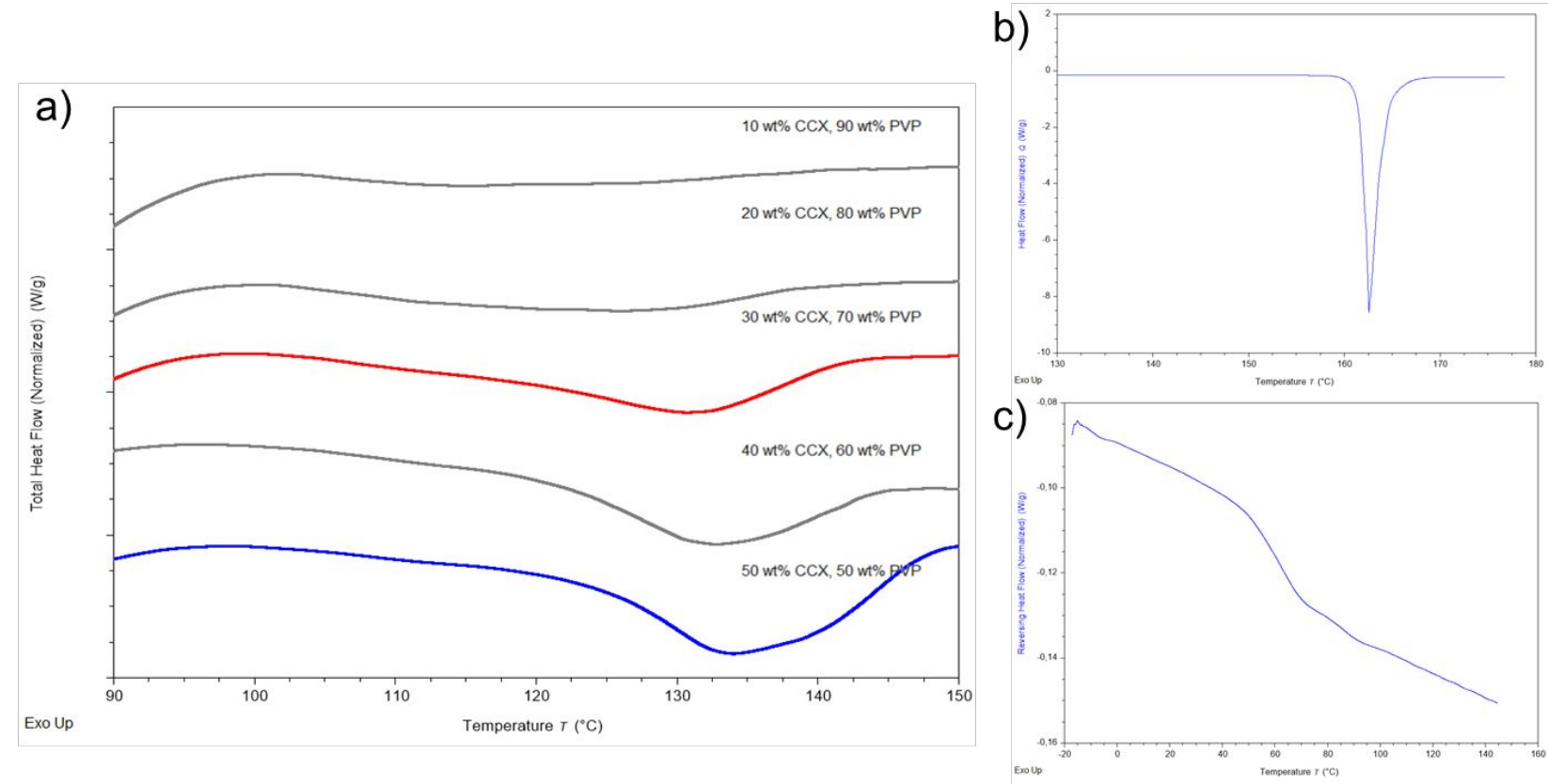

Figure S5: a) Onset of fusion for mixtures of $10-50$ wt $\%$ celecoxib (CCX) mixtures with PVP from the DSC calibration fitting. The $y$-axis is adjusted for the overlay and without scaling. Exo up. B) Thermogram of pure CCX for comparison. C) Thermogram of PVP (containing the water of the bulk polymer) for comparison. 
Figure 56:

a)

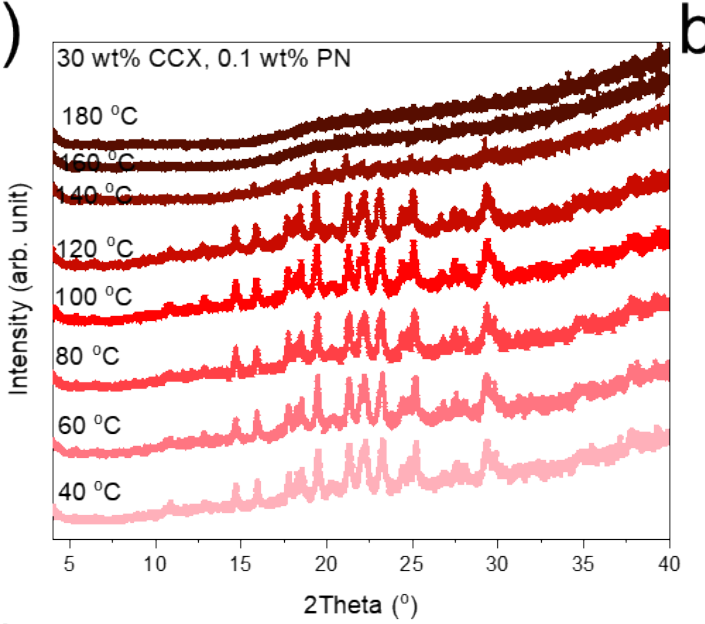

c)

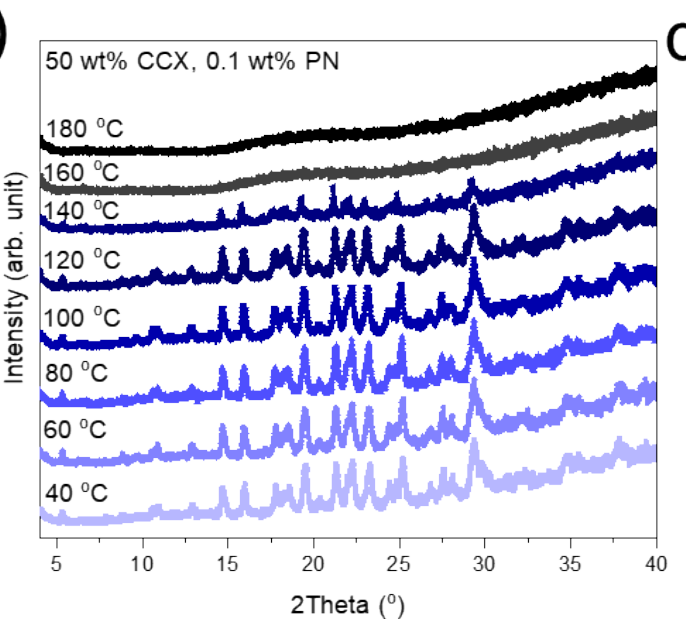

b)

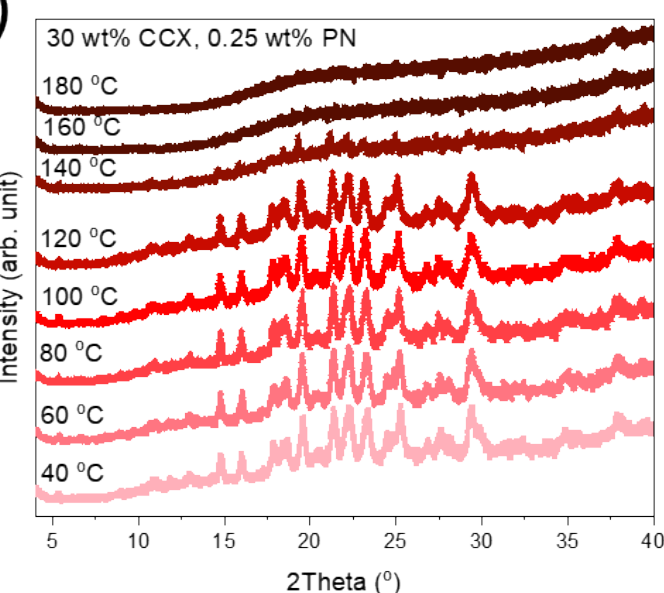

d)

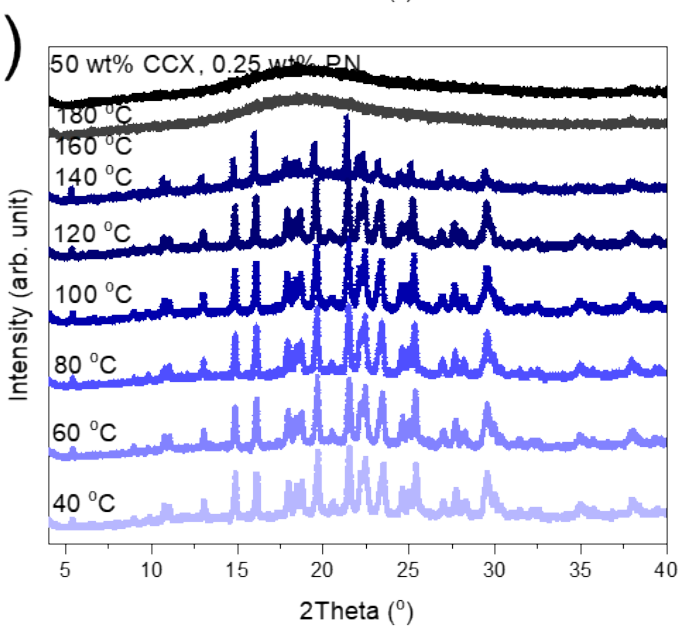

e)

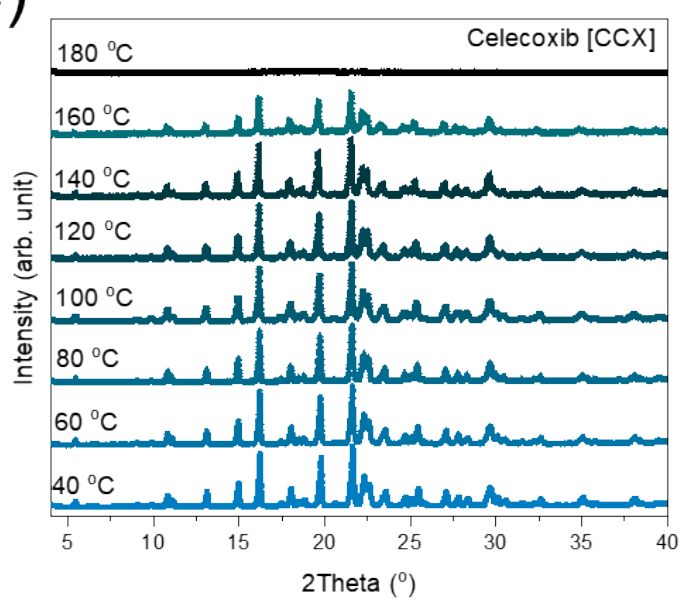

Figure S6: Diffractograms obtained using a variable temperature stage; a) 50 wt $\%$ celecoxib (CCX), 0.1 wt \% plasmonic nanoparticles (PN) mixture; b) 50 wt $\%$ CCX, 0.25 wt $\%$ PN mixture; c) 30 wt $\%$ CCX, 0.1 wt $\%$ PN mixture; d) $30 \mathrm{wt} \%$ CCX, $0.25 \mathrm{wt} \%$ PN mixture; e) pure CCX. The lowest temperature starts at the bottom of each subfigure. 
Figure S7:

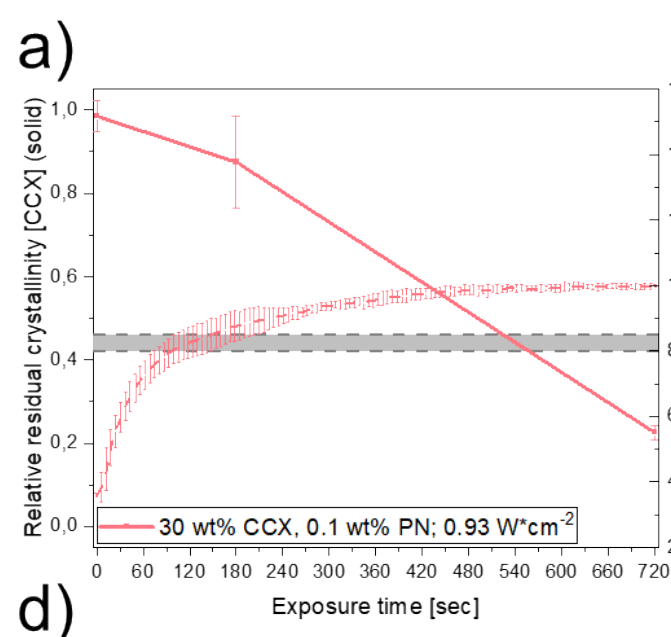

b)

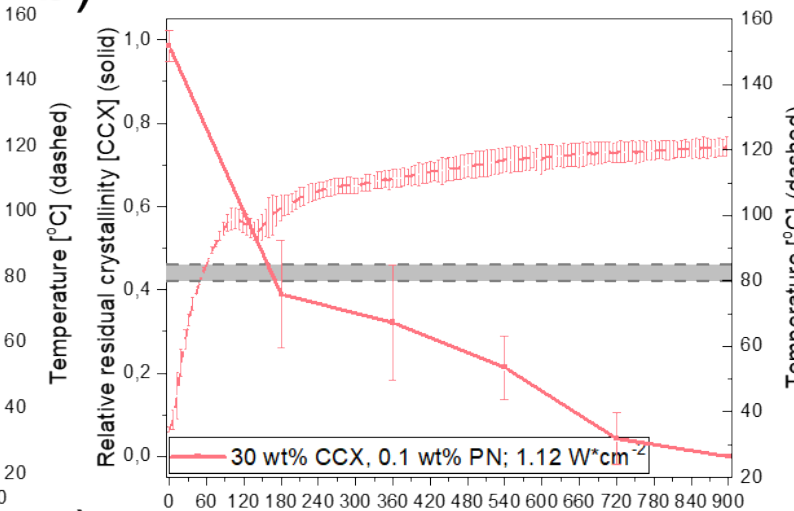

e)

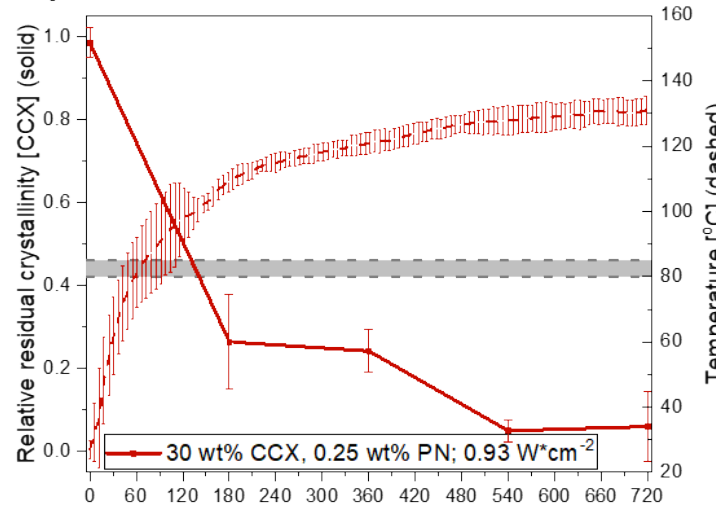

Exposure time $[\mathrm{sec}]$
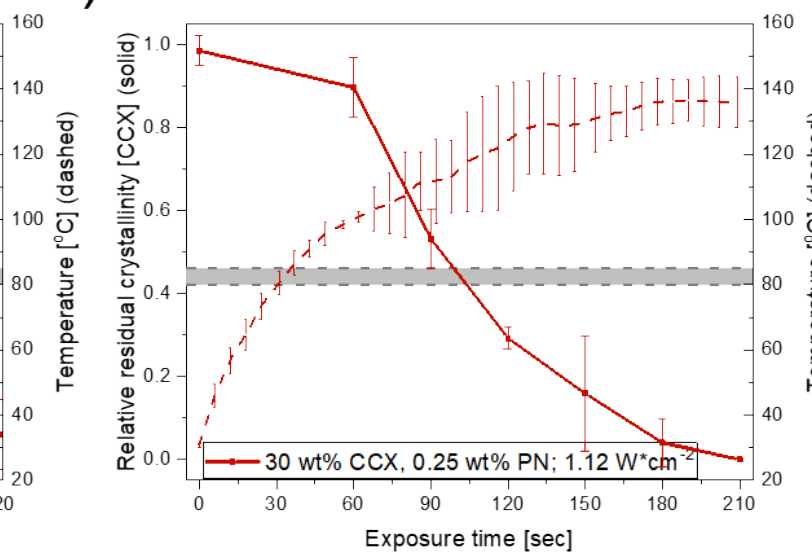

c)

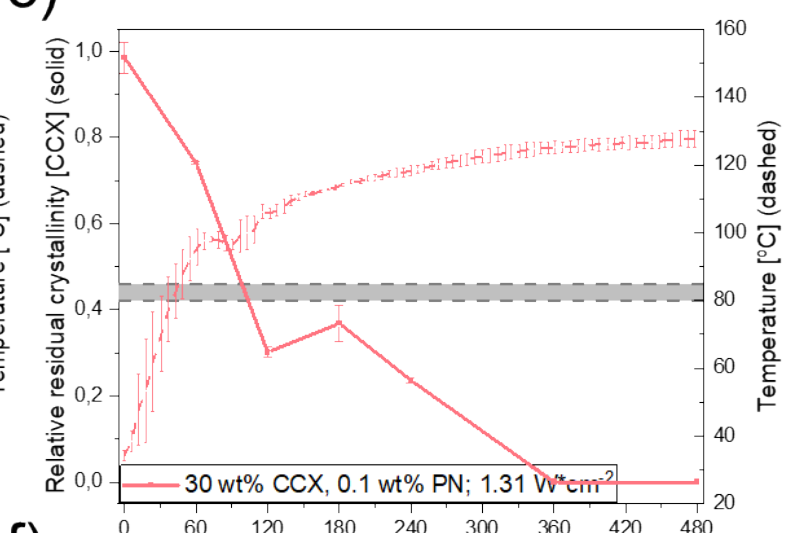

f)

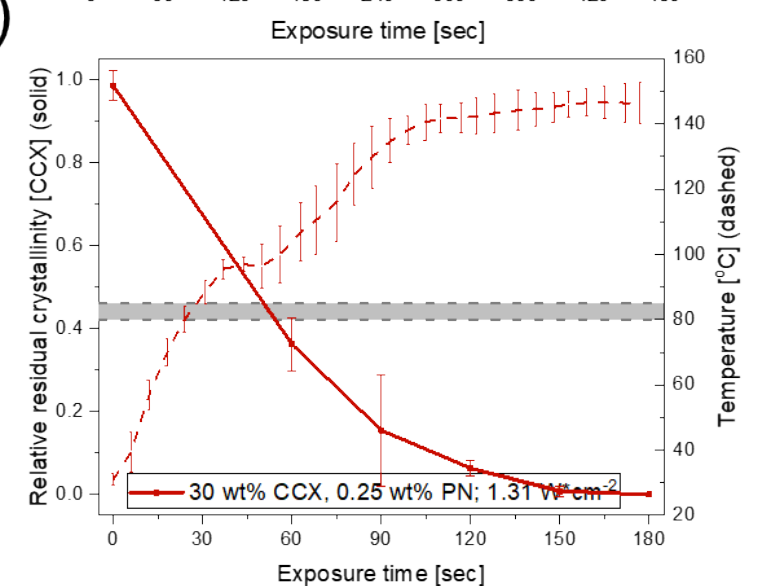

Figure S7: Relative residual crystallinity of celecoxib (CCX) (left y-axis, solid) and temperature (right y-axis, dashed) plotted against the exposure time for $30 \mathrm{wt} \%$ drug load. A) $0.1 \mathrm{wt} \%$ plasmonic nanoparticles (PN); laser intensity $0.93 \mathrm{~W} \mathrm{~cm}^{-2}$; b) $0.1 \mathrm{wt} \% \mathrm{PN}$; laser intensity $1.12 \mathrm{~W} \mathrm{~cm}^{-2}$; c) $0.1 \mathrm{wt} \% \mathrm{PN}$; laser intensity $1.31 \mathrm{~W} \mathrm{~cm}^{-2}$; d) $0.25 \mathrm{wt} \% \mathrm{PN}$; laser intensity $0.93 \mathrm{~W} \mathrm{~cm}-2$; e) $0.25 \mathrm{wt}^{2} \% \mathrm{PN}$; laser intensity $\left.1.12 \mathrm{~W} \mathrm{~cm}{ }^{-2} ; \mathrm{f}\right) 0.25 \mathrm{wt} \%$ $\mathrm{PN}$; laser intensity $1.31 \mathrm{~W} \mathrm{~cm}^{-2}$. Mean $\pm \mathrm{SD}(n=2)$ left $\mathrm{y}$-axis and Mean $\pm \mathrm{SD}(n=3)$ right $\mathrm{y}$-axis. The dashed grey lines indicate the critical temperature threshold. The reader is made aware of that the $\mathrm{x}$-axis have different scales. 
a)

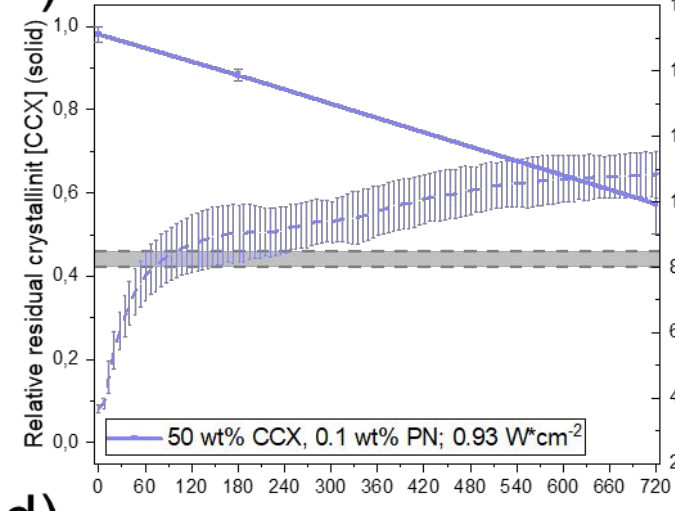

d) Exposure time [sec]

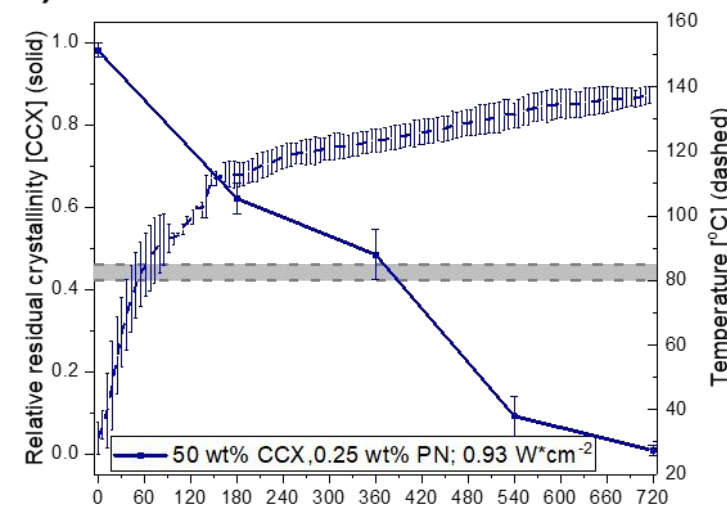
Exposure time [sec] b)

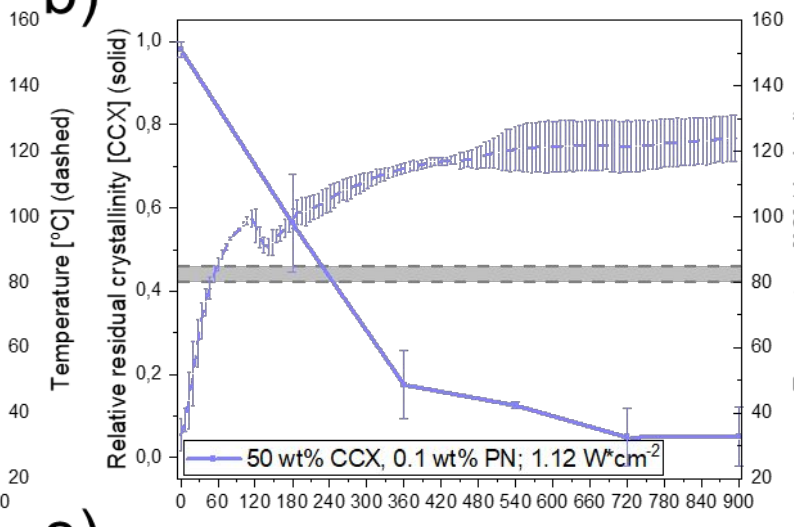

e)
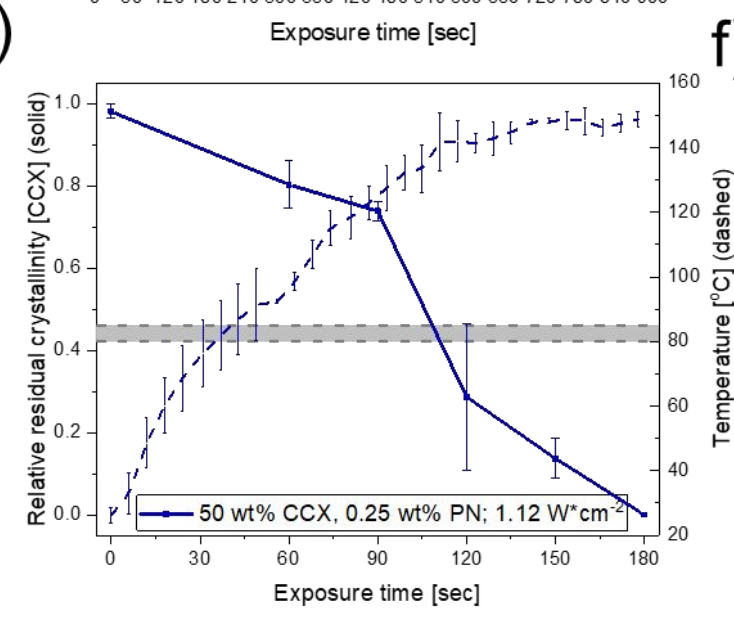

c)

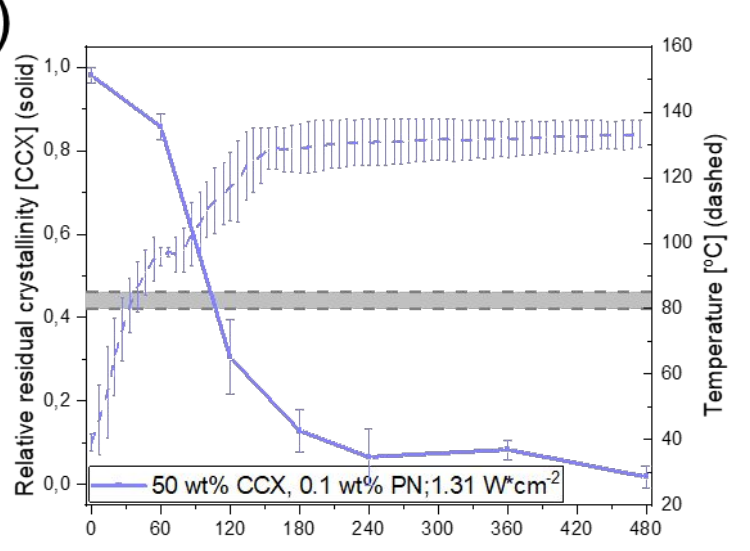

f)

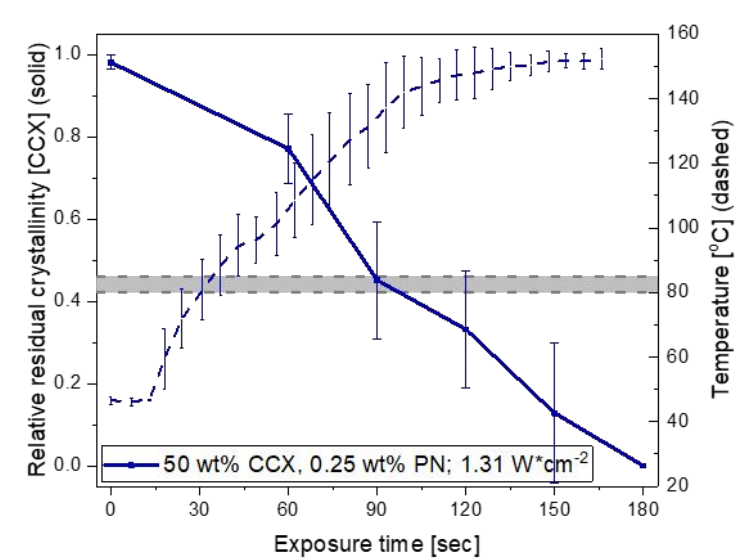

Figure S8: Relative residual crystallinity of celecoxib (CCX) (left y-axis, solid) and temperature (right y-axis, dashed) plotted against the exposure time for $50 \mathrm{wt} \%$ drug load. A) $0.1 \mathrm{wt} \%$ plasmonic nanoparticles (PN); laser intensity $0.93 \mathrm{~W} \mathrm{~cm}^{-2}$; b) $0.1 \mathrm{wt} \% \mathrm{PN}$; laser intensity $1.12 \mathrm{~W} \mathrm{~cm}^{-2}$; c) $0.1 \mathrm{wt} \% \mathrm{PN}$; laser intensity $1.31 \mathrm{~W} \mathrm{~cm}^{-2}$; d) $0.25 \mathrm{wt} \% \mathrm{PN}$; laser intensity $0.93 \mathrm{~W} \mathrm{~cm}-2$; e) $0.25 \mathrm{wt}^{2} \% \mathrm{PN}$; laser intensity $1.12 \mathrm{~W} \mathrm{~cm}-2$; f) $0.25 \mathrm{wt}^{2} \%$ $\mathrm{PN}$; laser intensity $1.31 \mathrm{~W} \mathrm{~cm}^{-2}$. Mean $\pm \mathrm{SD}(n=2)$ left y-axis and Mean $\pm \mathrm{SD}(n=3)$ right $\mathrm{y}$-axis. The dashed grey lines indicate the critical temperature threshold. The reader is made aware of that the $\mathrm{x}$-axis have different scales. 
Figure S9:
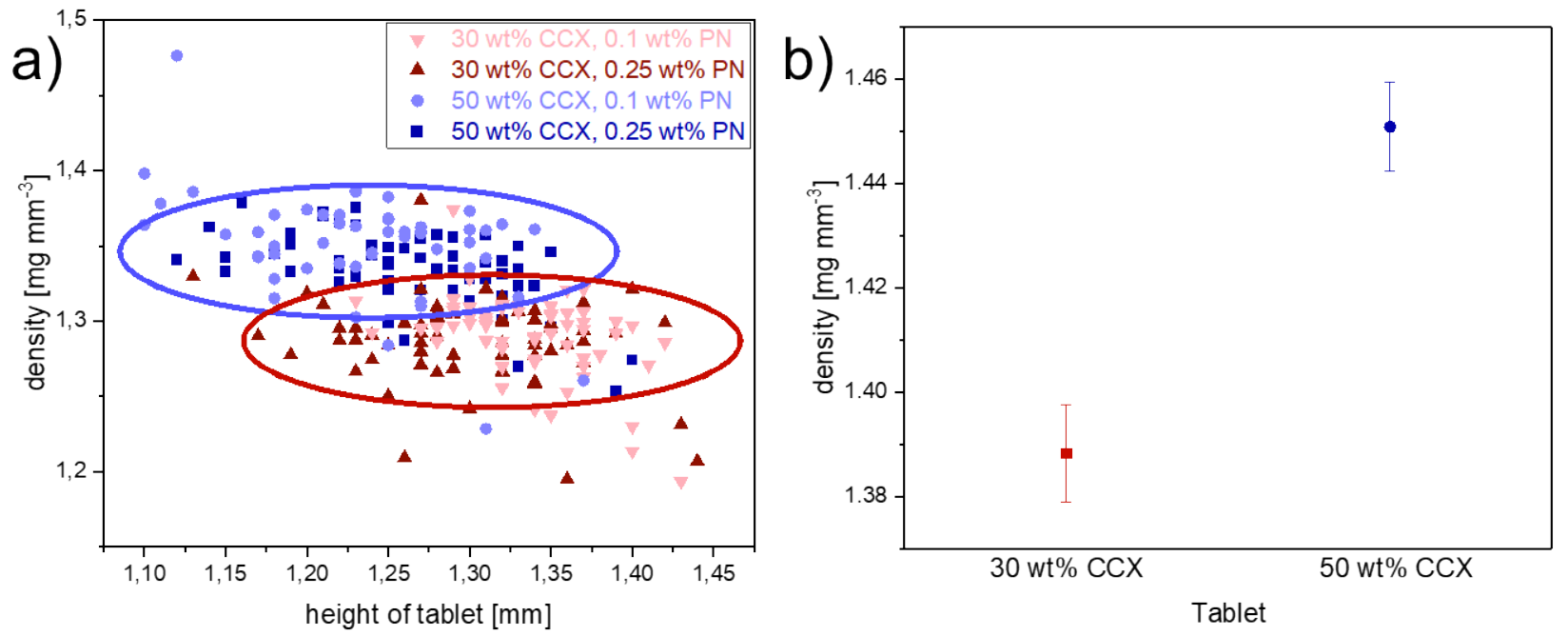

Figure S9: Density measurements obtained by a) measuring the height and the weight of the tablet before exposure to laser radiation and by b) using a helium pycnometer. CCX: celecoxib; PN: plasmonic nanoparticles. 
Figure S10:

a)

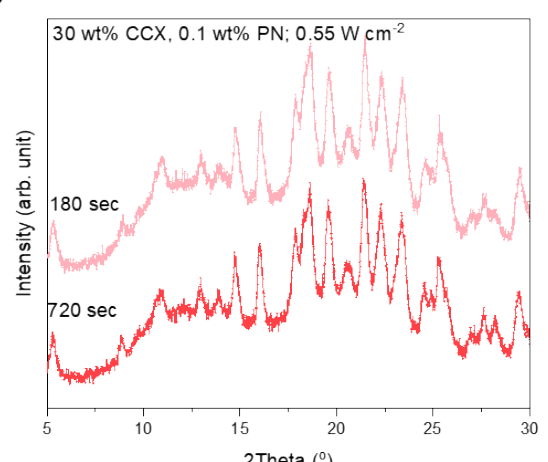

d)

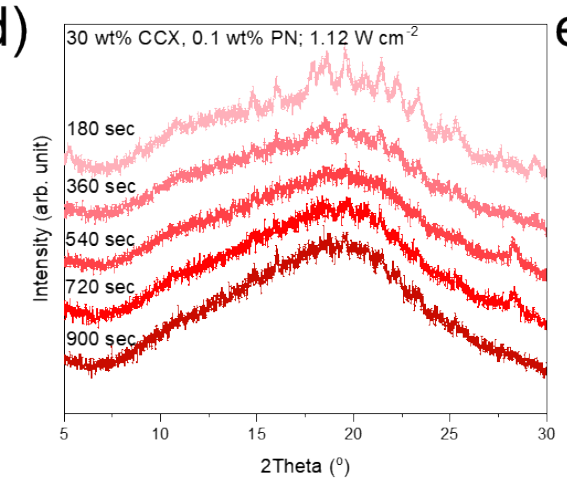

b)

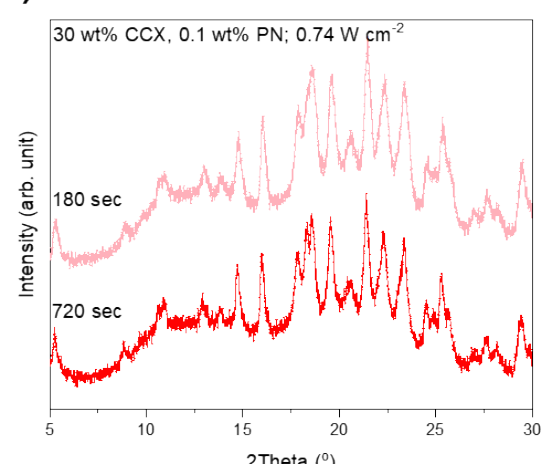

c)

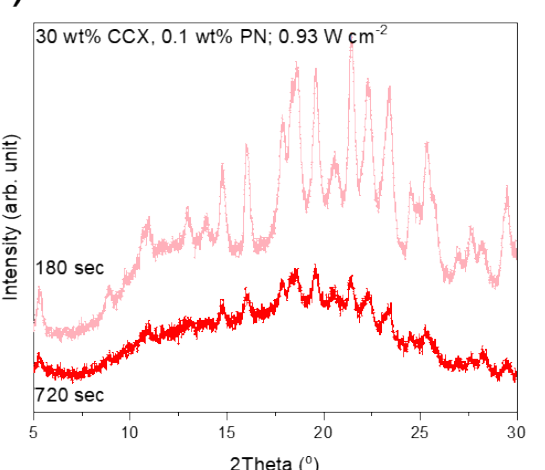

g)

e) $30 \mathrm{wt} \% \mathrm{ccX}, 0.1 \mathrm{wt} \% \mathrm{PN} ; 1.31 \mathrm{wcm}^{-2}$

f) $30 \mathrm{wt} \% \mathrm{cCX}, 0.1 \mathrm{wt} \% \mathrm{PN} ; 180 \mathrm{sec}$

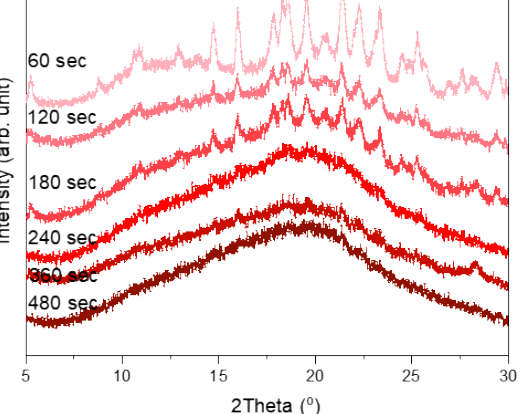

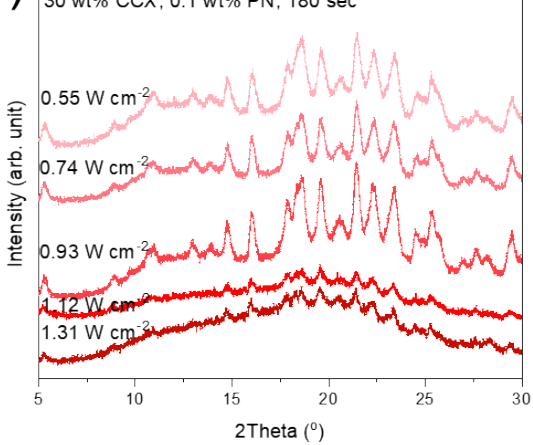

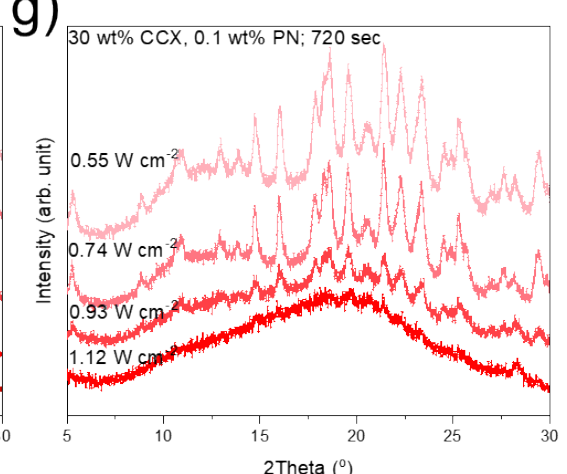

Figure S10: X-ray diffractograms of tablets exposed to laser radiation with $30 \mathrm{wt}^{2}$ celecoxib (CCX) and $0.1 \mathrm{wt} \%$ plasmonic nanoparticles (PN). A) laser intensity $\left.0.55 \mathrm{~W} \mathrm{~cm}^{-2} ; \mathrm{b}\right)$ laser intensity $0.74 \mathrm{~W} \mathrm{~cm}^{-2} ; \mathrm{c}$ ) laser intensity $0.93 \mathrm{~W} \mathrm{~cm}^{-2}$; d) laser intensity $1.12 \mathrm{~W} \mathrm{~cm}^{-2}$; e) laser intensity $1.31 \mathrm{~W} \mathrm{~cm}^{-2}$; a-e) increasing exposure times; f) exposure time 180 sec for different laser intensity; g) exposure time 720 sec for different laser intensity; 
Figure S11:

a)

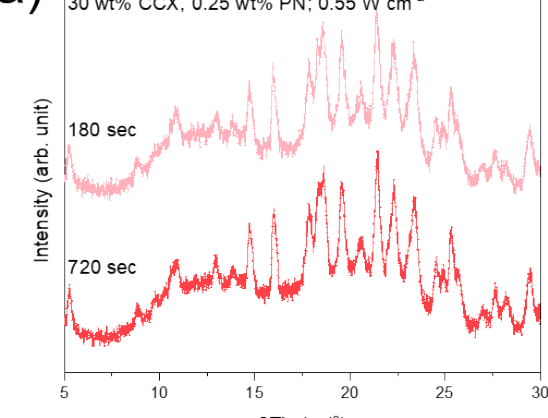

d)

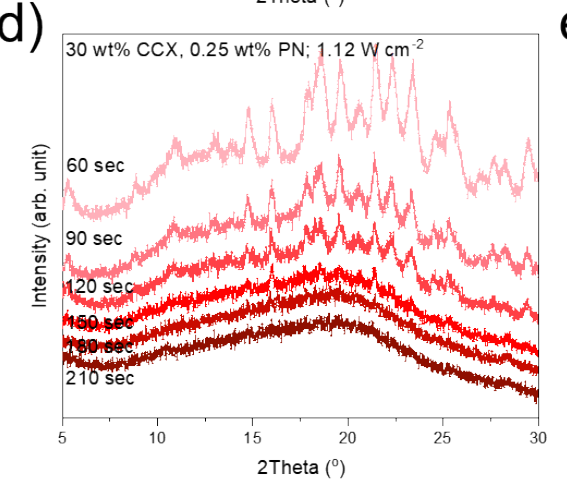

b)

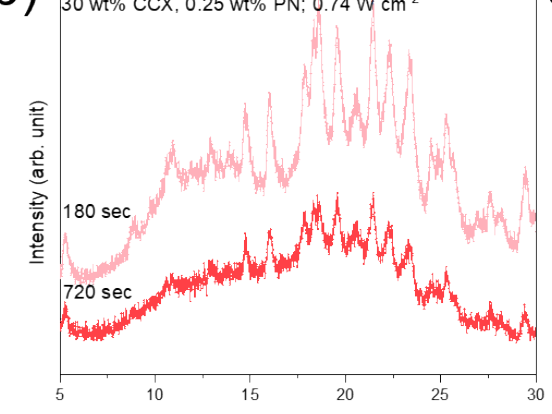

e)

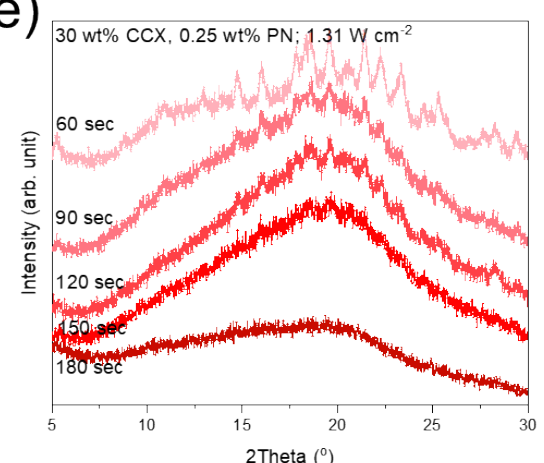

c)

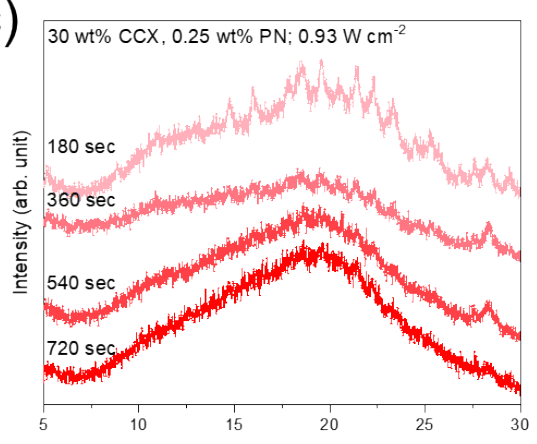

f)

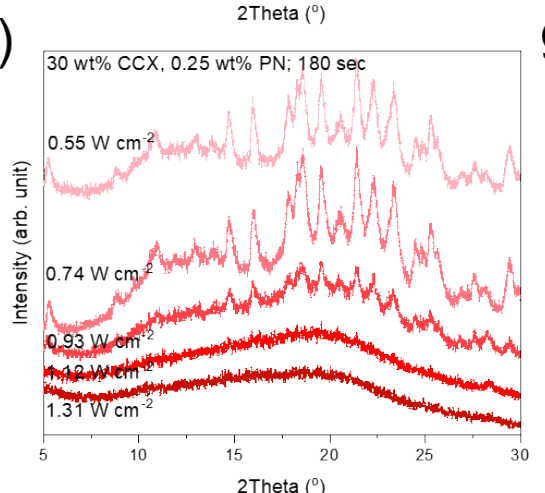

g)

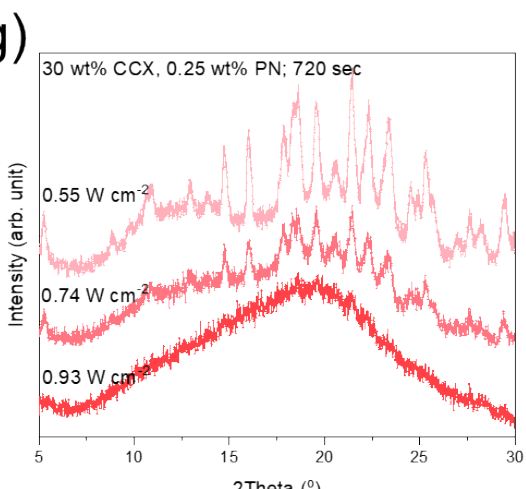

Figure S11: X-ray diffractograms of tablets exposed to laser radiation with $30 \mathrm{wt} \%$ celecoxib (CCX) and $0.25 \mathrm{wt} \%$ plasmonic nanoparticles (PN). A) laser intensity $0.55 \mathrm{~W} \mathrm{~cm}^{-2} ;$ b) laser intensity $0.74 \mathrm{~W} \mathrm{~cm}^{-2} ; \mathrm{c}$ ) laser intensity $0.93 \mathrm{~W} \mathrm{~cm}^{-2}$; d) laser intensity $1.12 \mathrm{~W} \mathrm{~cm}^{-2} ;$ e) laser intensity $1.31 \mathrm{~W} \mathrm{~cm}^{-2} ; \mathrm{a}-\mathrm{e}$ ) increasing exposure times; f) exposure time 180 sec for different laser intensity; g) exposure time 720 sec for different laser intensity; 
a)

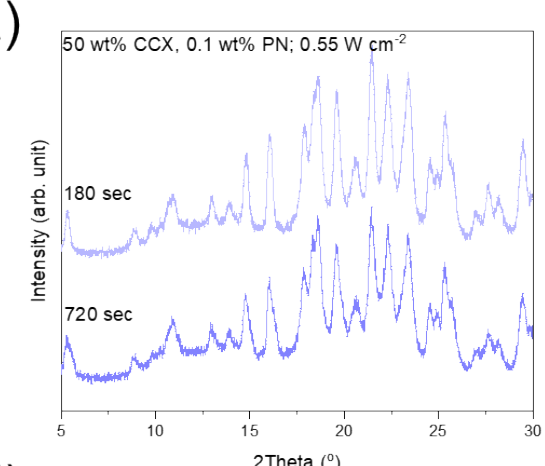

d)

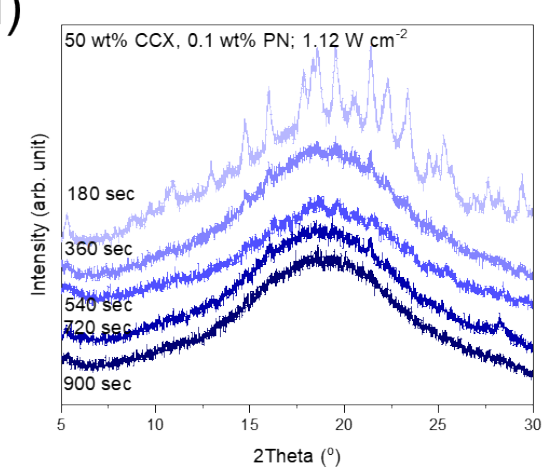

b)

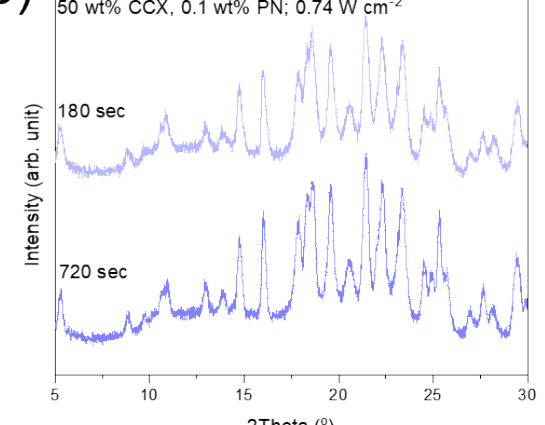

e)

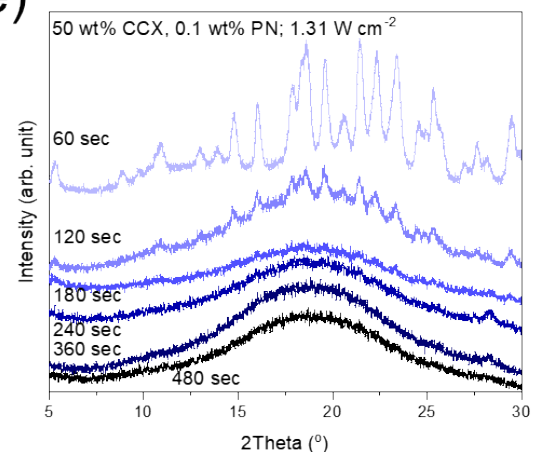

c)

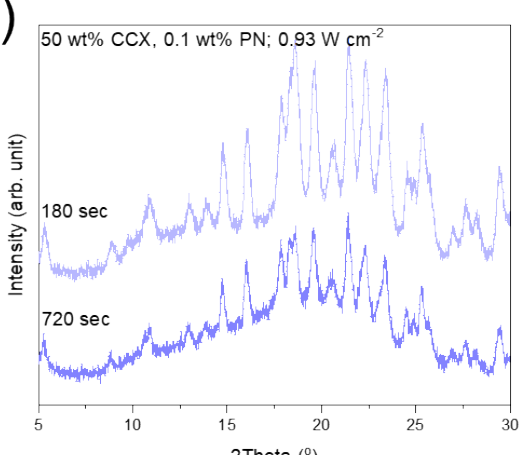

f)

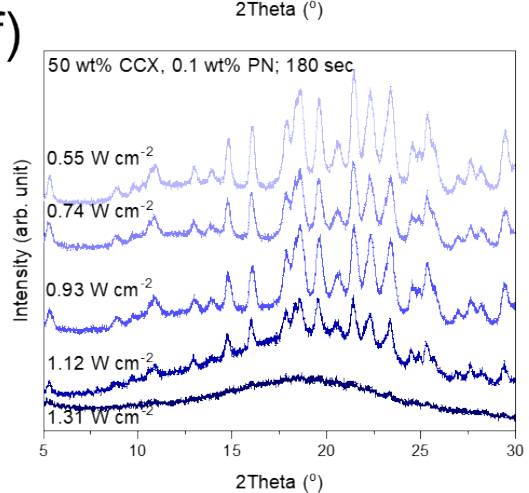

g)

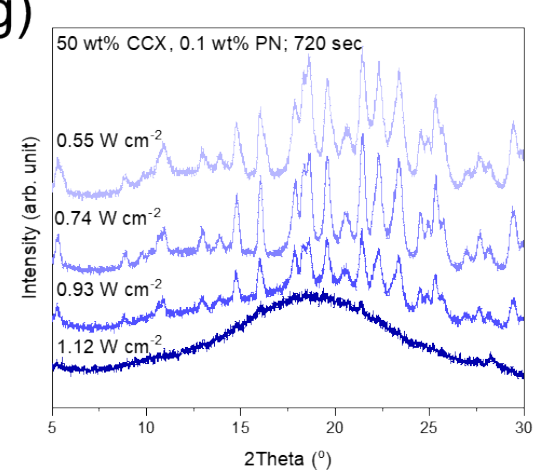

Figure S12: X-ray diffractograms of tablets exposed to laser radiation with $50 \mathrm{wt}^{2}$ celecoxib (CCX) and $0.1 \mathrm{wt} \%$ plasmonic nanoparticles (PN). A) laser intensity $0.55 \mathrm{~W} \mathrm{~cm}^{-2} ;$ b) laser intensity $0.74 \mathrm{~W} \mathrm{~cm}^{-2} ; \mathrm{c}$ ) lase intensity $0.93 \mathrm{~W} \mathrm{~cm}^{-2} ;$ d) laser intensity $1.12 \mathrm{~W} \mathrm{~cm}^{-2}$; e) laser intensity $1.31 \mathrm{~W} \mathrm{~cm}^{-2}$; a-e) increasing exposure times; f) exposure time 180 sec for different laser intensity; g) exposure time 720 sec for different laser intensity; 
a)

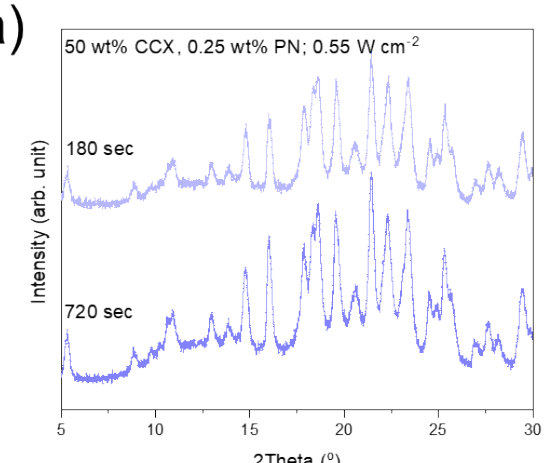

d)

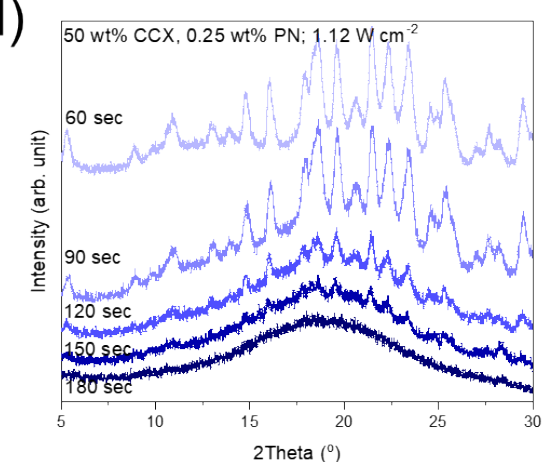

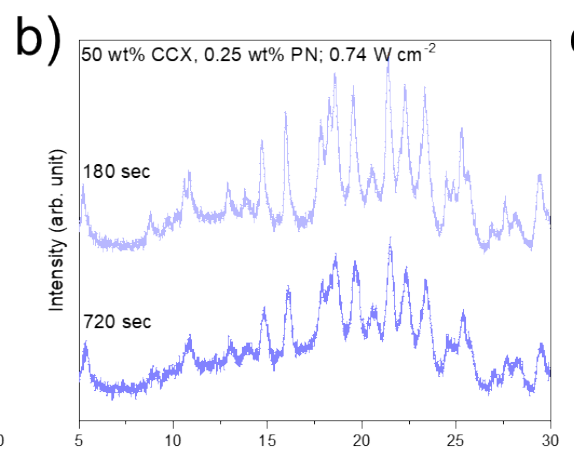

e)

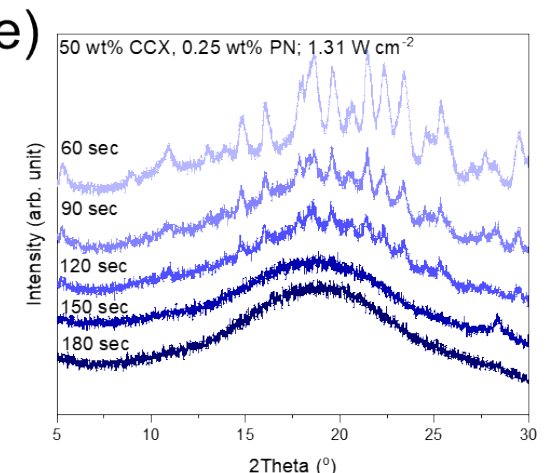

c)

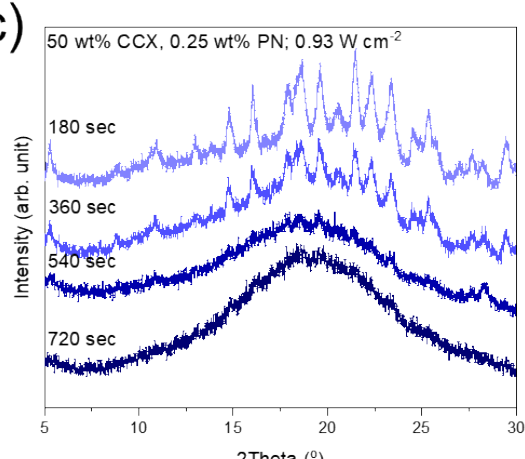

f)

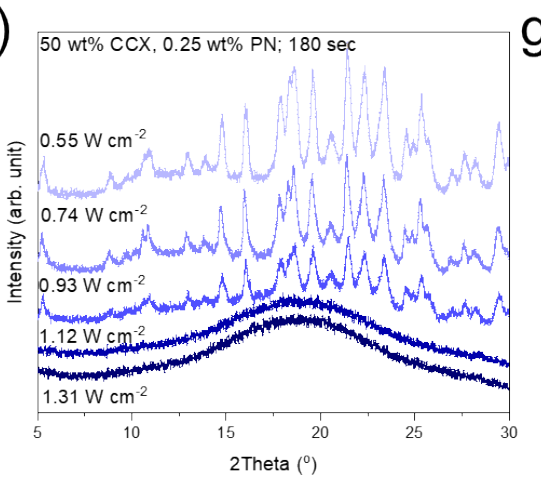

g)

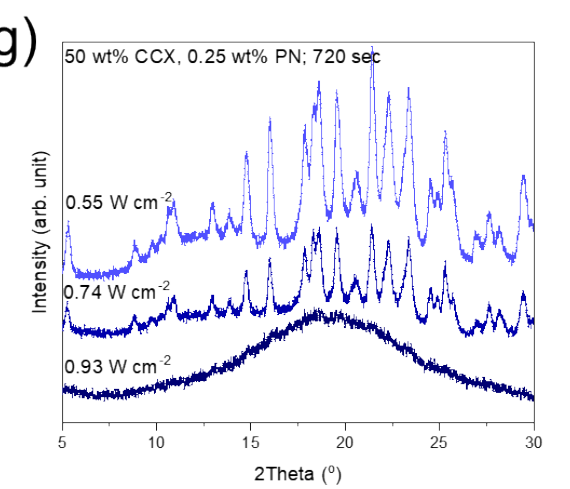

Figure S13: X-ray diffractograms of tablets exposed to laser radiation with $50 \mathrm{wt} \%$ celecoxib (CCX) and $0.25 \mathrm{wt} \%$ plasmonic nanoparticles (PN). A) laser intensity $\left.0.55 \mathrm{~W} \mathrm{~cm}^{-2} ; \mathrm{b}\right)$ laser intensity $0.74 \mathrm{~W} \mathrm{~cm}^{-2} ; \mathrm{c}$ ) laser intensity $0.93 \mathrm{~W} \mathrm{~cm}^{-2}$; d) laser intensity $1.12 \mathrm{~W} \mathrm{~cm}^{-2} ;$ e) laser intensity $1.31 \mathrm{~W} \mathrm{~cm}^{-2}$; a-e) increasing exposure times; f) exposure time 180 sec for different laser intensity; g) exposure time 720 sec for different laser intensity; 


\section{Table S5:}

The complete amorphous ASD obtained as described in Table S4 were additionally characterized by measuring their glass transition temperature $\left(T_{\mathrm{g}}\right)$. Since only a single $T_{\mathrm{g}}$ was obtained for the tablets after exposure to laser radiation, the formation of a homogenous ASD is suggested (Table S5). As the tablets contain residual water after exposure to laser radiation (Table S6), the $T_{\mathrm{g}}$ was lowered compared to the measured $T_{\mathrm{g}}$ for water-free ASDs.

Phase-separation or recrystallization could potentially happen during the cooling of the ASD to room temperature. It was found, that the tablets cool down to below their $T_{\mathrm{g}} \mathrm{s}$ in less than $30 \mathrm{sec}$ after exposure to laser radiation (data not shown).

Table S5: Glass transition temperatures $\left(T_{\mathrm{g}} \mathrm{s}\right)$ of tablets exposed to laser radiation. CCX: celecoxib; PN: plasmonic nanoparticles. The $T_{\mathrm{g}}$ is given as Mean \pm SD $(n=2)$.

\begin{tabular}{|l|l|l|l|}
\hline Tablet composition & Laser intensity $\left[\mathbf{W ~} \mathbf{~ c m}^{-2}\right]$ & Exposure time $[\mathbf{s e c}]$ & $\mathbf{T}_{\mathbf{g}}\left[{ }^{\circ} \mathbf{C}\right]$ \\
\hline $\mathbf{3 0} \mathbf{w t} \% \mathbf{C C X}, \mathbf{0 . 1} \mathbf{w t} \% \mathbf{P N} ;$ & 1.31 & 480 & $74.85 \pm 0.04$ \\
\hline $\mathbf{3 0} \mathbf{w t} \% \mathbf{C C X}, \mathbf{0 . 1} \mathbf{w t} \% \mathbf{P N}$ & 1.12 & 900 & $73.75 \pm 1.14$ \\
\hline $\mathbf{3 0} \mathbf{w t} \% \mathbf{C C X}, \mathbf{0 . 2 5} \mathbf{w t} \% \mathbf{P N}$ & 1.31 & 180 & $76.63 \pm 6.02$ \\
\hline $\mathbf{3 0} \mathbf{w t} \% \mathbf{C C X}, \mathbf{0 . 2 5} \mathbf{w t} \% \mathbf{P N}$ & 1.12 & 180 & $76.92 \pm 1.15$ \\
\hline $\mathbf{3 0} \mathbf{w t} \% \mathbf{C C X}, \mathbf{0 . 2 5} \mathbf{w t} \% \mathbf{P N}$ & 0.93 & 720 & $82.12 \pm 6.12$ \\
\hline $\mathbf{5 0} \mathbf{w t} \% \mathbf{C C X}, \mathbf{0 . 1} \mathbf{w t} \% \mathbf{P N}$ & 1.31 & 480 & $78.76 \pm 0.03$ \\
\hline $\mathbf{5 0} \mathbf{w t} \% \mathbf{C C X}, \mathbf{0 . 1} \mathbf{w t} \% \mathbf{P N}$ & 1.12 & 900 & $79.76 \pm 0.73$ \\
\hline $\mathbf{5 0} \mathbf{w t} \% \mathbf{C C X}, \mathbf{0 . 2 5} \mathbf{w t} \% \mathbf{P N}$ & 1.31 & 180 & $80.64 \pm 3.07$ \\
\hline $\mathbf{5 0} \mathbf{w t} \% \mathbf{C C X}, \mathbf{0 . 2 5} \mathbf{w t} \% \mathbf{P N}$ & 1.12 & 180 & $80.28 \pm 2.23$ \\
\hline $\mathbf{5 0} \mathbf{w t} \% \mathbf{C C X}, \mathbf{0 . 2 5} \mathbf{w t} \% \mathbf{P N}$ & 0.93 & 720 & $77.57 \pm 0.94$ \\
\hline
\end{tabular}




\section{Table S6:}

Table S6: Water content (wt \%) of tablets exposed to laser radiation $(n=1)$. The results are given in [\%]. The left column indicates the tablet composition and the laser intensity, the upper row indicates the exposure time [sec]. CCX: celecoxib; PN: plasmonic nanoparticles.

\begin{tabular}{|c|c|c|c|c|c|c|c|c|c|}
\hline 50 wt $\%$ CCX, 0.25 wt $\%$ PN & \multicolumn{9}{|c|}{ Exposure time [sec]/ Water content [\%] } \\
\hline Laser intensity $\left[\mathrm{W} \mathrm{\textrm {cm } ^ { - 2 } ]}\right.$ & 60 & 90 & 120 & 150 & 180 & 360 & 540 & 720 & \\
\hline 1.31 & 0.79 & 2.10 & 1.74 & 1.61 & 1.38 & & & & \\
\hline 1.12 & 2.24 & 2.12 & 1.50 & 1.45 & 1.19 & & & & \\
\hline 0.93 & & & & & 2.11 & 1.86 & 1.41 & 1.35 & \\
\hline 0.74 & & & & & 2.69 & & & 2.30 & \\
\hline 0.55 & & & & & 2.83 & & & 2.50 & \\
\hline 50 wt $\%$ CCX, 0.1 wt $\%$ PN & \multicolumn{9}{|c|}{ Exposure time [sec] / Water content [\%] } \\
\hline Laser intensity [W $\left.\mathrm{cm}^{-2}\right]$ & 60 & 120 & 180 & 240 & 360 & 480 & 540 & 720 & 900 \\
\hline 1.31 & 2.47 & 1.71 & 1.31 & 1.46 & 1.25 & 1.20 & & & \\
\hline 1.12 & & & 1.92 & & 1.49 & & 1.43 & 1.38 & 1.24 \\
\hline 0.93 & & & 2.36 & & & & & 1.97 & \\
\hline 0.74 & & & 2.51 & & & & & 2.38 & \\
\hline 0.55 & & & 2.44 & & & & & 2.38 & \\
\hline 30 wt $\%$ CCX, 0.25 wt $\%$ PN & \multicolumn{9}{|c|}{ Exposure time [sec] / Water content [\%] } \\
\hline Laser intensity $\left[\mathrm{W} \mathrm{cm}{ }^{-2}\right]$ & 60 & 90 & 120 & 150 & 180 & 210 & 360 & 540 & 720 \\
\hline 1.31 & 1.85 & 1.86 & 1.86 & 1.76 & 0.92 & & & & \\
\hline 1.12 & 3.53 & 3.70 & 3.03 & 2.96 & 2.91 & 2.13 & & & \\
\hline 0.93 & & & & & 2.91 & & 2.54 & 2.40 & 0.96 \\
\hline 0.74 & & & & & 3.10 & & & & 2.93 \\
\hline 0.55 & & & & & 3.22 & & & & 3.15 \\
\hline $30 w t \%$ CCX, 0.1 wt $\%$ PN & \multicolumn{9}{|c|}{ Exposure time [sec] / Water content [\%] } \\
\hline Laser intensity [W cm $\left.\mathrm{cm}^{-2}\right]$ & 60 & 120 & 180 & 240 & 360 & 480 & 540 & 720 & 900 \\
\hline 1.31 & 3.03 & 2.63 & 2.50 & 2.27 & 2.26 & 2.00 & & & \\
\hline 1.12 & & & 2.57 & & 2.36 & & 2.46 & 2.30 & 2.16 \\
\hline 0.93 & & & 3.33 & & & & & 2.43 & \\
\hline 0.74 & & & 3.06 & & & & & 2.68 & \\
\hline 0.55 & & & 3.49 & & & & & 2.89 & \\
\hline
\end{tabular}




\section{Figure S14:}
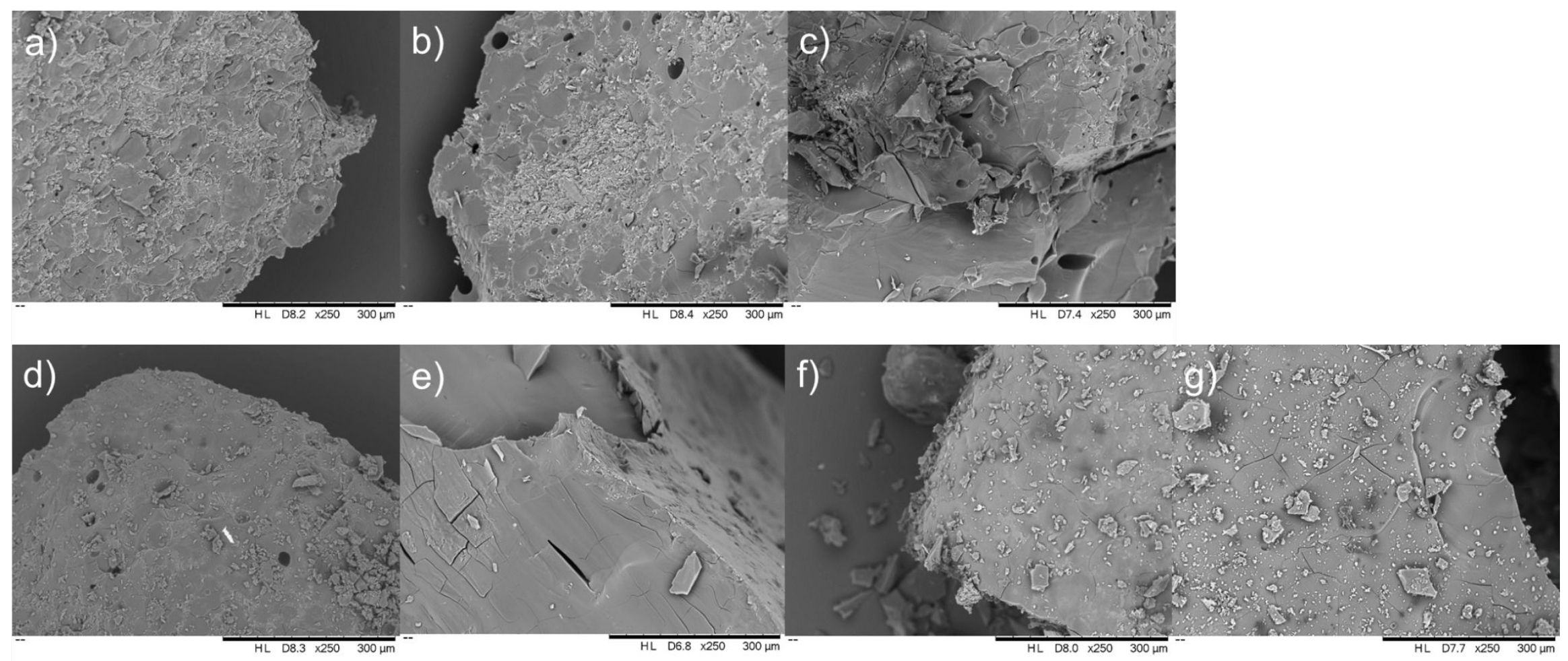

Figure S14: SEM Images of a tablet with $30 \mathrm{wt} \%$ celecoxib (CCX) and $0.1 \mathrm{wt} \%$ plasmonic nanoparticles (PN); a) before exposure to laser radiation, and afterexposure to a laser intensity of $1.31 \mathrm{~W} \mathrm{~cm}^{-2}$ for b) 60 sec, $\mathrm{c}$ ) $120 \mathrm{sec}$; d) $180 \mathrm{sec}$; e) $240 \mathrm{sec}$;) $360 \mathrm{sec}$ and g) $480 \mathrm{sec}$; magnification x250-fold. From a) to g) the morphology of the tablet is first rough and becomes smoother with increasing exposure times indicating the formation of an ASD. 


\section{Figure S15:}
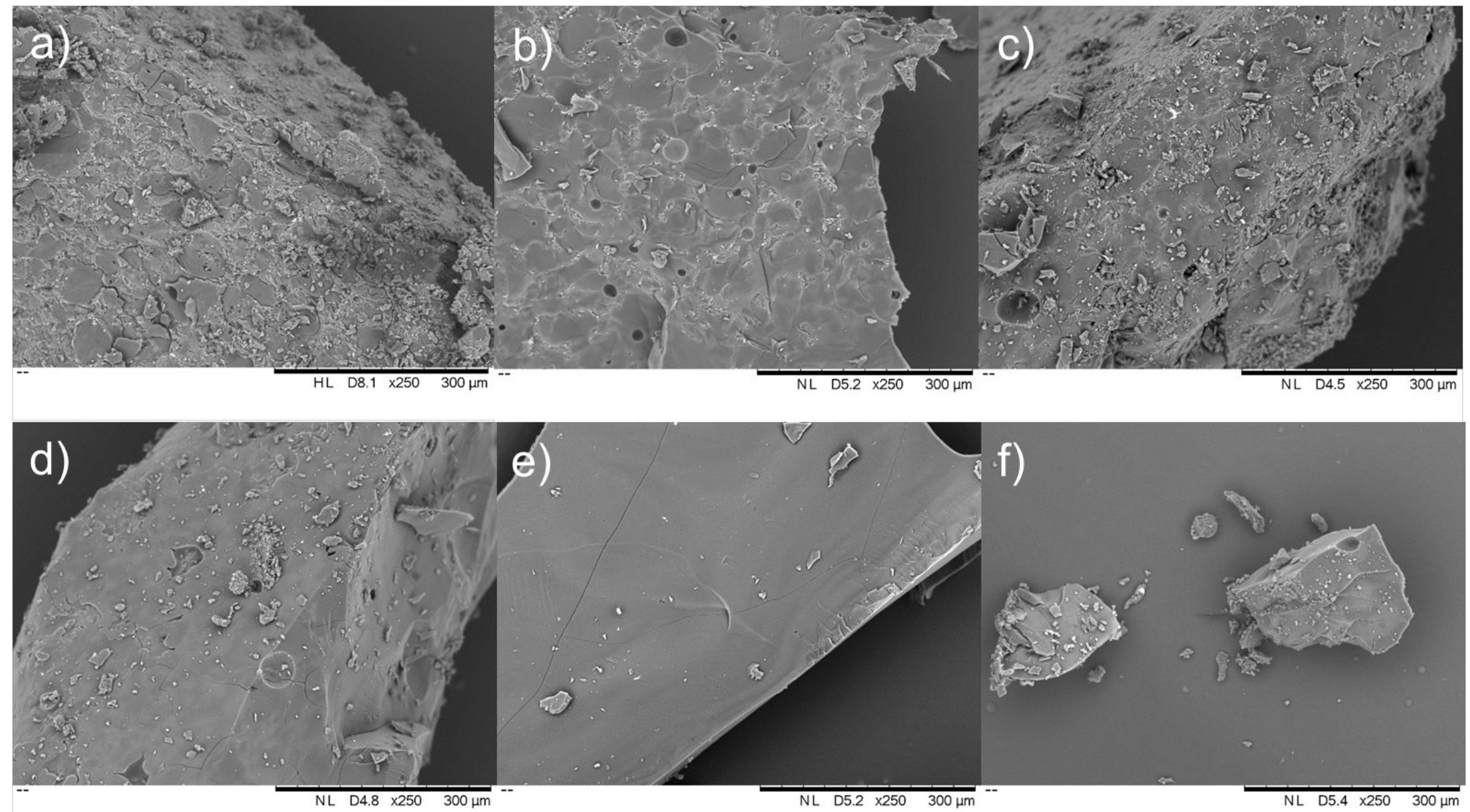

Figure S15: SEM Images of a tablet with $30 \mathrm{wt} \%$ celecoxib (CCX) and $0.25 \mathrm{wt} \%$ plasmonic nanoparticles (PN); a) before exposure to laser radiation, and after exposure to a laser intensity of $1.31 \mathrm{~W} \mathrm{~cm}^{-2}$ for b) 60 sec c) $90 \mathrm{sec}$; d) $120 \mathrm{sec}$; e) $150 \mathrm{sec}$ and f) $180 \mathrm{sec}$; magnification $\times 250$-fold. From a) to f) the morphology of the tablet is first rough and becomes smoother with increasing exposure times indicating the formation of an ASD. 


\section{Figure S16:}

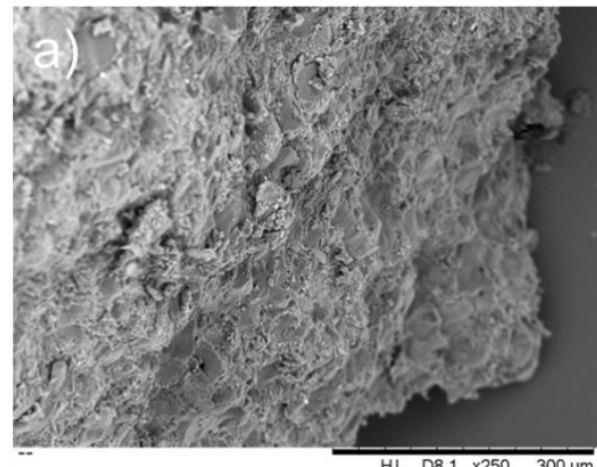

b)

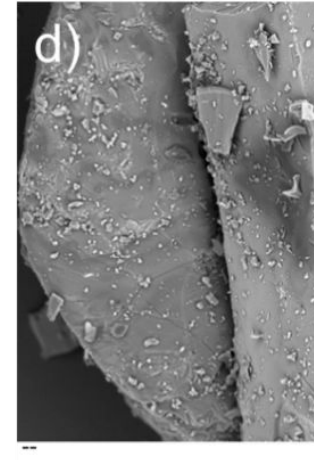

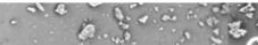
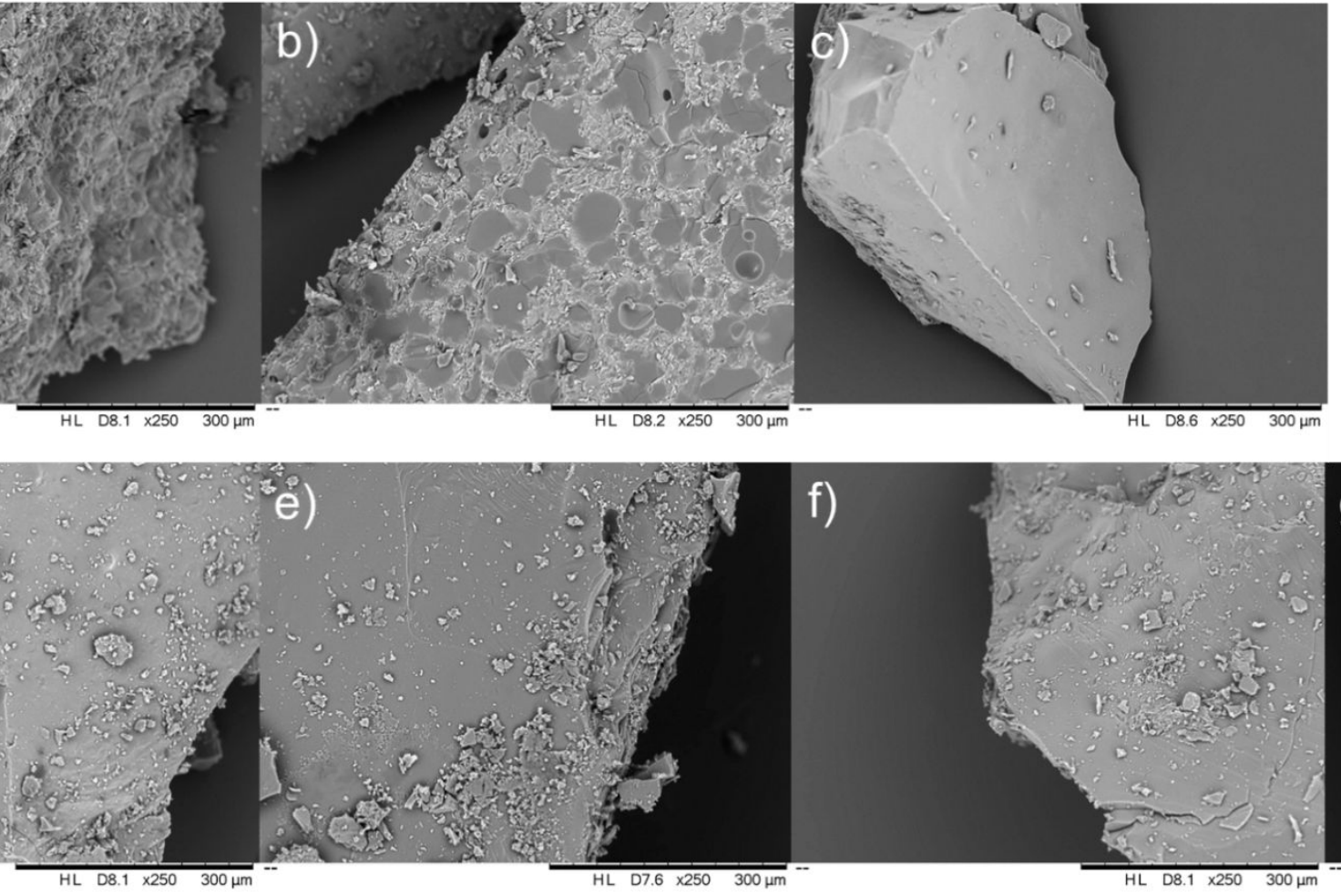

HL D8.2 $\times 250 \quad 300 \mu \mathrm{m}$

HL D8.6 $\times 250300 \mu \mathrm{m}$

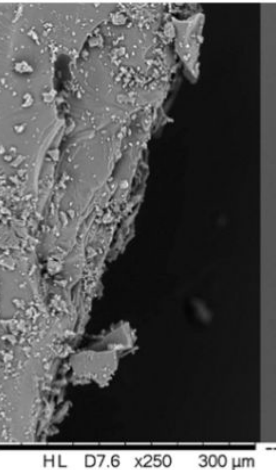

f)

Figure S16: SEM Images of the tablet with $50 \mathrm{wt} \%$ celecoxib (CCX) and $0.1 \mathrm{wt} \%$ plasmonic nanoparticles (PN); a) before exposure to laser radiation, and after exposure to a laser intensity of $1.31 \mathrm{~W} \mathrm{~cm}-2$ for b) 60 sec, c) $120 \mathrm{sec}$; d) $180 \mathrm{sec}$; e) $240 \mathrm{sec}$; f) $360 \mathrm{sec}$ and g) $480 \mathrm{sec}$; magnification $\times 250$-fold. From a) to g) the morphology of the tablet is first rough and becomes smoother with increasing exposure times indicating the formation of an ASD. 

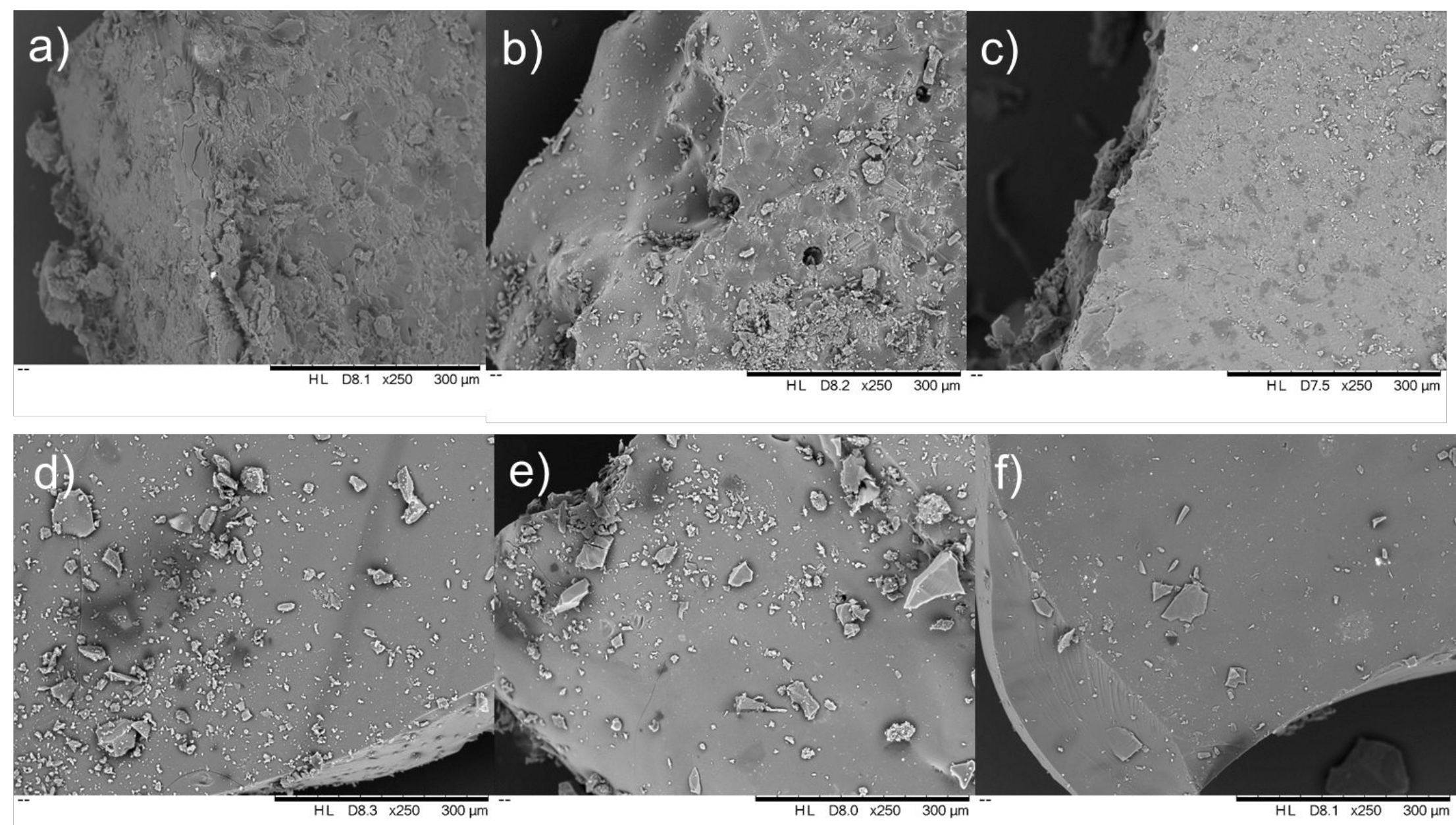

Figure S17: SEM Images of a tablet with $50 \mathrm{wt} \%$ celecoxib (CCX) and $0.25 \mathrm{wt} \%$ plasmonic nanoparticles (PN); a) before exposure to laser radiation, and after exposure to a laser intensity of $1.31 \mathrm{~W} \mathrm{~cm}{ }^{-2}$ for b) 60 sec c) $90 \mathrm{sec}$; d) $120 \mathrm{sec}$; e) $150 \mathrm{sec}$ and f) $180 \mathrm{sec}$; magnifaction x 250 -fold. From a) to f) the morphology of the tablet is first rough and becomes smoother with increasing exposure times indicating the formation of an ASD. 


\section{Table S7:}

Table S7 shows the results obtained by HPLC. Neither could any degradation products be detected in the chromatogram, nor could any loss in CCX. The CCX content after laser exposure matches the determined CCX content before laser exposure inside the tablets.

Table S7: Quantification of celecoxib inside tablets exposed and not exposed to laser radiation determined by HPLC ( $n=3)$. CCX: celecoxib; PN: plasmonic nanoparticles.

\begin{tabular}{|c|c|c|c|}
\hline Tablet composition & Laser intensity [ $\left.\mathrm{W} \mathrm{cm}^{-2}\right]$ & Exposure time [sec] & wt $\%$ of CCX (Mean \pm SD, $n=3$ ) \\
\hline 30 wt\% CCX, no PN & 1.12 & 900 & $30.23 \pm 0.16$ \\
\hline 30 wt $\%$ CCX, no PN & 1.31 & 480 & $26.70 \pm 0.08$ \\
\hline 30 wt $\%$ CCX, 0.1 wt $\%$ PN & 1.12 & 900 & $31.35 \pm 0.04$ \\
\hline 30 wt $\%$ CCX, 0.1 wt $\%$ PN & 1.31 & 480 & $32.19 \pm 0.16$ \\
\hline 30 wt $\%$ CCX, 0.25 wt $\%$ PN & 0.93 & 720 & $33.02 \pm 0.04$ \\
\hline 30 wt $\%$ CCX, 0.25 wt $\%$ PN & 1.12 & 210 & $30.41 \pm 0.13$ \\
\hline 30 wt $\%$ CCX, 0.25 wt $\%$ PN & 1.31 & 180 & $30.50 \pm 0.18$ \\
\hline 50 wt $\%$ CCX, 0.1 wt $\%$ PN & 1.12 & 900 & $52.55 \pm 0.11$ \\
\hline 50 wt\% CCX, 0.1 wt\% PN & 1.31 & 480 & $49.05 \pm 0.02$ \\
\hline 50 wt $\%$ CCX, 0.25 wt $\%$ PN & 0.93 & 720 & $49.98 \pm 0.02$ \\
\hline 50 wt $\%$ CCX, 0.25 wt $\%$ PN & 1.12 & 180 & $50.10 \pm 0.24$ \\
\hline 50 wt $\%$ CCX, 0.25 wt $\%$ PN & 1.31 & 180 & $47.45 \pm 0.19$ \\
\hline 30 wt $\%$ CCX, 0.1 wt $\%$ PN & - & - & $29.32 \pm 0.44$ \\
\hline 30 wt $\%$ CCX, 0.25 wt $\%$ PN & - & - & $30.22 \pm 1.11$ \\
\hline 50 wt $\%$ CCX, 0.1 wt $\%$ PN & - & - & $45.06 \pm 3.04$ \\
\hline 50 wt $\%$ CCX, 0.25 wt $\%$ PN & - & - & $48.52 \pm 0.95$ \\
\hline
\end{tabular}

\section{MS Results:}

A full MS from $150.070 \mathrm{~g} / \mathrm{mol}$ to $400.000 \mathrm{~g} / \mathrm{mol}$ was conducted to exclude oxidation upon exposure to laser radiation. The main CCX peaks are found at 381.63, 382.05, 382.47 (largest peak) and $382.68 \mathrm{~m} / \mathrm{z}$. Three main fragmentation products were identified, which could not be detected in tablets exposed to laser radiation. The fragmentation products are suggested to be: 4(3-(difluoromethyl)-5-(p-tolyl)-1H-pyrazol-1-yl)-benzenesulfonamide (363.09 m/z), 4-(5-(p-tolyl)-1H-pyrazol-1-yl)benzenesulfonamide $(313.38 \mathrm{~m} / \mathrm{z}$ ) and 4-(5-phenyl-1H-pyrazol-1-yl)-benzenesulfonamide $(234.12 \mathrm{~m} / \mathrm{z})$. Only the CCX peak could be identified in the MS spectra from tablets exposed to laser radiation. 


\section{Figure S18:}

Figure S18 shows X-ray diffractograms of tablets before exposure to laser radiation and tablets without PN exposed to laser radiation. It can be seen that similar diffractograms are obtained indicating little or no amorphization of tablets without PN exposed to laser radiation.

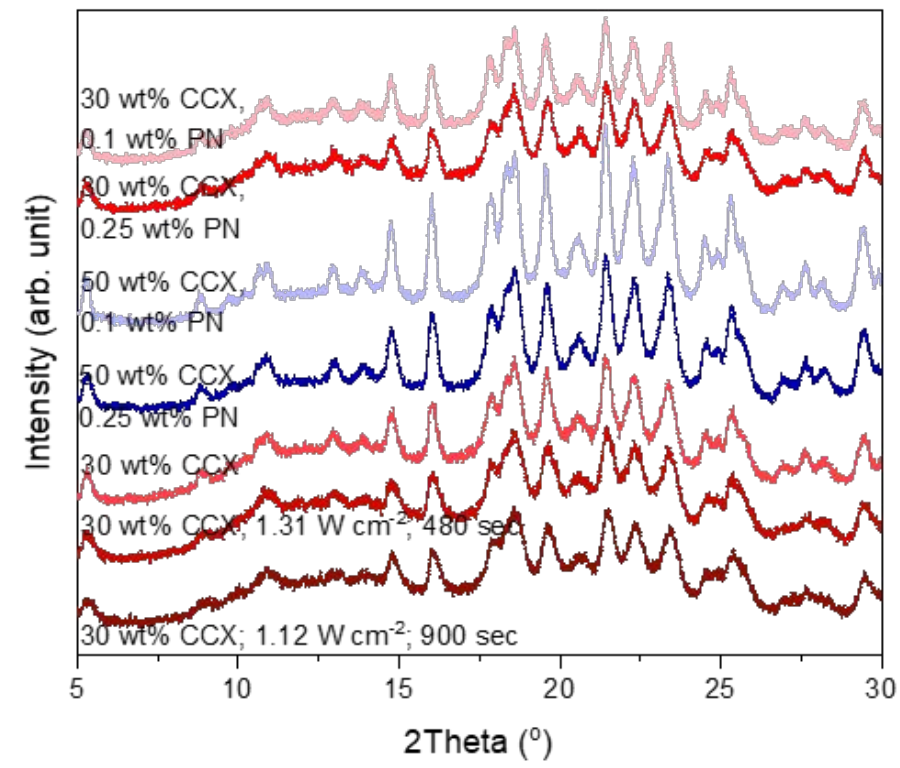

Figure S18: X-ray diffractograms of tablets before exposure to laser radiation and tablets without plasmonic nanoparticles (PN) exposed to laser radiation 


\section{Table S8:}

The tablets contained small amounts of water due to the hygroscopicity of the polymer PVP. The water content was similar in all tablets (Table S8). Upon heating of the tablets, the water will start to evaporate upon heating up until $100{ }^{\circ} \mathrm{C}$ (Figure S7 and S8). The evaporation of the water from the top (facing the laser) of the tablet caused a cooling effect on the surface, therefore the temperature decreased shortly.

Table S8: Water content (wt $\%)$ of the tablets prior to laser radiation $(n=3)$. CCX: celecoxib; PN: plasmonic nanoparticles.

\begin{tabular}{|l|l|}
\hline Tablet composition & Water content (Mean \pm SD $(\boldsymbol{n}=\mathbf{3}))[\%]$ \\
\hline $\mathbf{3 0}$ wt $\%$ CCX, 0.1 wt\% PN & $4.82 \pm 0.32$ \\
\hline $\mathbf{3 0} \mathbf{w t} \% \mathbf{C C X}, \mathbf{0 . 2 5} \mathbf{w t} \%$ PN & $4.95 \pm 0.40$ \\
\hline $\mathbf{5 0} \mathbf{w t} \% \mathbf{C C X}, \mathbf{0 . 1} \mathbf{w t} \%$ PN & $3.30 \pm 0.29$ \\
\hline $\mathbf{5 0} \mathbf{w t} \% \mathbf{C C X}, \mathbf{0 . 2 5} \mathbf{w t} \%$ PN & $3.41 \pm 0.14$ \\
\hline
\end{tabular}

\section{Figure S19:}

Figure S19 shows the viability of Caco-2 cells after exposure to Ag nanoparticles (PN) for $24 \mathrm{~h}$ at different concentrations. It can be seen that no significant cytotoxicity was found below $100 \mu \mathrm{g} \mathrm{mL} \mathrm{L}^{-1} \mathrm{PN}$.

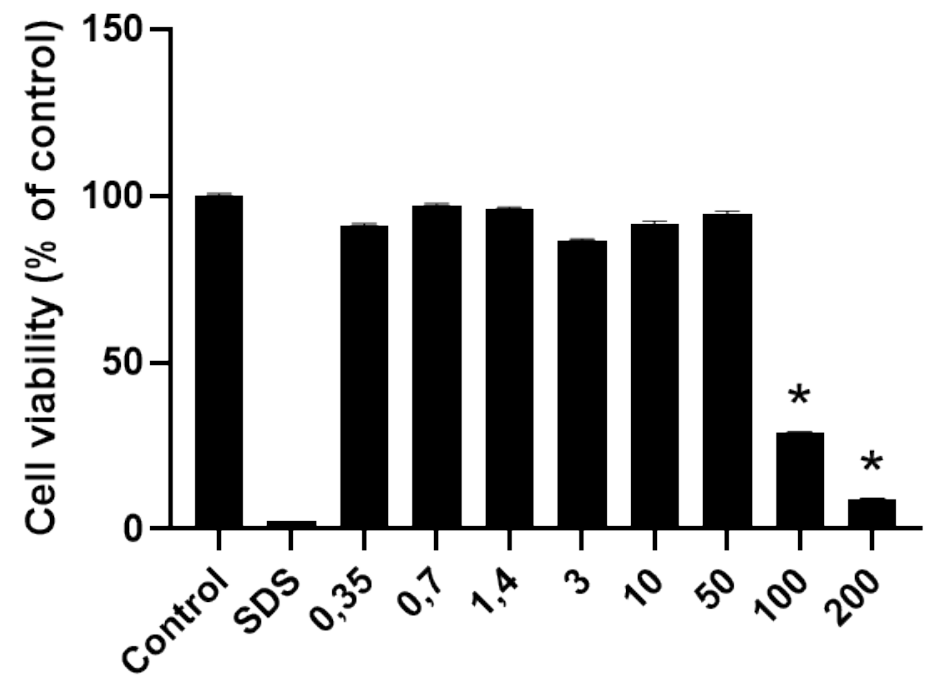

Ag NP (ug/ml)

Figure S19: Viability of Caco-2 cells after exposure for $24 \mathrm{~h}$ to Ag nanoparticles at concentrations of $0.35200 \mu \mathrm{g} \mathrm{mL}-1$ using the WST1 cytotoxicity assay. The data are presented as the mean \pm SD of two independent experiments $(n=12)$. Differences were calculated by $t$ test $\left({ }^{*} p<0,05\right)$.

\section{References}

[1] M. I. Noordin, L. Y. Chung, Drug Dev Ind Pharm 2004, 30, 925-930.

[2] C. T. Moynihan, A. J. Easteal, J. Wilder, J. Tucker, J. Phys. Chem. 1974, 78, 2673-2677.

[3] G. Roudaut, D. Simatos, D. Champion, E. Contreras-Lopez, M. Le Meste, Innov Food Sci Emerg 2004, 5, 127-134.

[4] D. E. Moseson, L. S. Taylor, Int J Pharm 2018, 553, 454-466.

[5] J. A. Baird, B. Van Eerdenbrugh, L. S. Taylor, J. Pharm. Sci. 2010, 99, 3787-3806. 